\title{
Leaf chlorophyll constraint on model simulated Gross Primary Productivity in agricultural systems
}

\author{
Rasmus Houborg* ${ }^{1}$, Matthew McCabe ${ }^{1}$, Alessandro Cescatti ${ }^{2}$, and Anatoly Gitelson ${ }^{3}$ \\ ${ }^{1}$ King Abdullah University of Science and Technology, Water Desalination and Reuse Center, Kingdom \\ of Saudi Arabia \\ ${ }^{2}$ European Commission, Joint Research Centre, IES, Ispra, Italy \\ ${ }^{3}$ Center for Advanced Land Management Information Technology (CALMIT), School of Natural \\ Resources, University of Nebraska-Lincoln, Lincoln, NE, USA
}

*Corresponding author:

Rasmus Houborg

Earth System Observation and Modelling Group

Environmental Sciences and Engineering Division

Water Desalination and Reuse Center

King Abdullah University of Science and Technology (KAUST)

Building 4, office 3262

P.O. Box 4090, Thuwal 23955

Kingdom of Saudi Arabia

Phone: +966128082237

Cell: +966 544700262

Email: rasmus.houborg@kaust.edu.sa 


\section{ABSTRACT}

Leaf chlorophyll content $\left(\mathrm{Chl}_{1}\right)$ may serve as an observational proxy for the maximum rate of carboxylation $\left(V_{\max }\right)$, which describes leaf photosynthetic capacity and represents the single most important control on modeled leaf photosynthesis within most Terrestrial Biosphere Models (TBMs). The parameterization of $V_{\max }$ is associated with great uncertainty as it can vary significantly between plants and in response to changes in leaf nitrogen $(\mathrm{N})$ availability, plant phenology and environmental conditions. Houborg et al. (2013) outlined a semi-mechanistic relationship between $V_{\max }^{25}\left(V_{\max }\right.$ normalized to $25^{\circ} \mathrm{C}$ ) and $\mathrm{Chl}_{1}$ based on inter-linkages between $V_{\text {max }}^{25}$, Rubisco enzyme kinetics, $\mathrm{N}$ and $\mathrm{Chl}_{1}$. Here, these relationships are parameterized for a wider range of important agricultural crops and embedded within the leaf photosynthesis-conductance scheme of the Community Land Model (CLM), bypassing the questionable use of temporally invariant and broadly defined plant functional type (PFT) specific $V_{\max }^{25}$ values. In this study, the new $\mathrm{Chl}_{1}$ constrained version of CLM is refined with an updated parameterization scheme for specific application to soybean and maize.

The benefit of using in-situ measured and satellite retrieved $\mathrm{Chl}_{1}$ for constraining model simulations of Gross Primary Productivity (GPP) is evaluated over fields in central Nebraska, U.S.A between 2001 and 2005. Landsat-based $\mathrm{Ch}_{1}$ time-series records derived from the Regularized Canopy Reflectance model (REGFLEC) are used as forcing to the CLM. Validation of simulated GPP against 15 site-years of flux tower observations demonstrate the utility of $\mathrm{Chl}_{1}$ as a model constraint, with the coefficient of efficiency increasing from 0.91 to 0.94 and from 0.87 to 0.91 for maize and soybean, respectively. Model performances particularly improve during the late reproductive and senescence stage, where the largest temporal variations in $\mathrm{Chl}_{1}$ (averaging $35-55 \mu \mathrm{g} \mathrm{cm}{ }^{-2}$ for maize and $20-35 \mu \mathrm{g} \mathrm{cm}^{-2}$ for soybean) are observed. While prolonged periods of vegetation stress did not occur over the studied fields, given the usefulness of $\mathrm{Chl}_{1}$ as an indicator of plant health, enhanced GPP predictabilities should be expected in fields exposed to longer periods of moisture and nutrient stress. While the results support the use of $\mathrm{Ch}_{1}$ as an observational proxy for $V_{\max }^{25}$, future work needs to be directed towards improving the $\mathrm{Ch}_{1}$ retrieval accuracy from space observations and developing consistent and physically realistic modeling schemes that can be parameterized with acceptable accuracy over spatial and temporal domains.

Keywords: Landsat; Leaf chlorophyll content; Vmax, leaf photosynthetic capacity; Community Land Model; Agriculture; Rubisco; Nitrogen 


\section{Introduction}

Chlorophyll pigments absorb photosynthetically active radiation (PAR) and therefore constitute a vital element in the photosynthetic process. Leaf chlorophyll content $\left(\mathrm{Chl}_{1}\right)$, defined here as total chlorophyll $a$ plus chlorophyll $b$ content on a one-sided leaf area basis, varies substantially in space and time and responds to changes in plant type (Gitelson et al., 2006a), environmental conditions (Evans, 1989), nutrient and water availability (Yamori et al., 2011) and plant phenology (Croft et al., 2014). Accordingly, $\mathrm{Ch}_{1}$ can be an important determinant of the overall plant physiological condition, serving as a critical proxy for plant stress (Zarco-Tejada et al., 2002), leaf nitrogen (Sage et al., 1987) and vegetation productivity (Gitelson et al., 2006b; Houborg et al., 2013; Schull et al., 2015). Reliable assessments of vegetation productivity, which may be referred to as Gross Primary Productivity (GPP), are useful for a diverse range of applications and studies related to agricultural management, precision farming, ecosystem monitoring and climate change. GPP has been estimated simply as a linear function of absorbed PAR and an empirical coefficient (light-use-efficiency, LUE) that describes the efficiency of plants in using the absorbed energy for photosynthesis, based on the semi-empirical approach of Monteith (1972). The simplicity of this approach makes it attractive in a remote sensing context (Gitelson et al., 2014; Running et al., 2004), but its success depends on correct specifications of canopy LUE in space and time and the relative importance of environmental and physiological constraints and feedback mechanisms not considered by the simple linear model.

State of the art terrestrial biosphere models (TBMs) are characterized by improved process understanding and descriptions for realistic simulation of biogeophysical and biogeochemical processes and exchanges of water, carbon and heat between the soil, vegetation and atmosphere. TBMs such as the Biosphere Energy Transfer Hydrology scheme (BETHY: Knorr, 2000), O-CN (Zaehle and Friend, 2010), the Joint Land Environment Stimulator (JULES: Clark et al., 2011) and the Community Land Model (CLM: Oleson et al., 2010), all embed coupled stomatal conductance and carbon assimilation models and leaf-tocanopy scaling schemes, to mechanistically reflect plant physiological responses to changes in atmospheric $\mathrm{CO}_{2}$, climate, environmental conditions and plant species. However, simulated land surface fluxes are highly sensitive to differences in modeling schemes (Chen et al., 2011) and adopted parameterizations over spatial and temporal domains (Groenendijk et al., 2011; Knorr and Heimann, 2001; Zaehle, 2005). The TBMs typically incorporate biochemical equations of $\mathrm{C}_{3}$ and $\mathrm{C}_{4}$ photosynthesis (Collatz et al., 1992, 1991; Farquhar et al., 1980), where the maximum rate of carboxylation at $25{ }^{\circ} \mathrm{C}$ $\left(V_{\text {max }}^{25}\right)$ represents the single most important parameter for estimating GPP (Bonan et al., 2011; Rogers, 2014; Verheijen et al., 2013). $V_{\max }$ is directly related to leaf concentration of the Rubisco enzyme that acts as a catalyst for carbon fixation, which in turn is strongly related to leaf nitrogen $(\mathrm{N})$ because of the 
large proportion of $\mathrm{N}$ in the photosynthetic machinery (Evans, 1989). Given the importance of this variable, there is a need to improve the parameterization of $V_{\max }^{25}$ in order to reduce uncertainties of model predicted carbon fluxes in space and time.

$V_{\max }$ can only be inferred at the leaf level, typically from fitting a model to leaf gas exchange measurements (Wullschleger et al., 1993; Sharkey et al., 2007) and exhibits considerable variation between and within species (Houborg et al., 2009; Wullschleger et al., 1993; Kattge and Knorr, 2007). Prescribing $V_{\max }^{25}$ with sufficient accuracy for model application over large areas with contrasting cover types and environmental conditions can be challenging and TBMs most often use time-invariant and plant functional type (PFT)-specific $V_{\max }^{25}$ values, which have been derived in a number of different ways leading to a lack of consensus in adopted values (Rogers, 2014). Recent advancements in the utilization of leaf nitrogen quantitative traits have enabled a more realistic and empirically grounded parameterization of PFT-specific $V_{\max }^{25}$ values (Kattge et al., 2011, 2009; Walker et al., 2014). However, photosynthetic capacity can differ markedly within each PFT due to spatio-temporal changes in $\mathrm{N}$ availability, plant phenology and climate conditions (Keenan et al., 2012; Xu and Baldocchi, 2003).

Remote sensing can support the implementation of TBMs by providing information on the spatial and temporal distribution of land surface vegetation characteristics important for constraining model simulations through better informed model parameterizations. $\mathrm{Chl}_{1}$ can be directly retrieved from satellite observed reflectances by inversion of leaf optical properties and canopy reflectance models (Jacquemoud et al., 2009) and since $\mathrm{Chl}_{1}$ has significant potential as an operational proxy for $\mathrm{N}$ (Homolová et al., 2013), satellite-based $\mathrm{Chl}_{1}$ may facilitate the needed observational constraint on leaf photosynthetic capacity (Houborg et al., 2013). However, the retrieval of $\mathrm{Chl}_{1}$ from remotely sensed canopy reflectance data is associated with fairly large uncertainties due to the influence of confounding factors from the atmosphere, canopy and soil, as well as the ill-posed nature of model inversion, which may result in non-unique solutions (Houborg et al., 2015).

Whether the retrievable accuracy of satellite-based $\mathrm{Chl}_{1}$ is sufficient for use in this context needs to be examined. This study attempts to investigate the utility of $\mathrm{Chl}_{1}$ as a proxy for $V_{\max }^{25}$ using an extensive dataset of both in-situ and satellite-retrieved $\mathrm{Chl}_{1}$ over maize and soybean sites in central Nebraska over a 5 -year period. The satellite-based records were previously derived from runs with the Regularized Canopy Reflectance model (REGFLEC) using 30 Landsat scenes as input (Houborg et al., 2015). A semimechanistic formulation for linking $\mathrm{Chl}_{1}$ to $V_{\max }^{25}$ (Houborg et al., 2013) is adopted here with a refined parameterization based on an extensive literature review for potential application over a wide suite of agricultural crops. The updated parameterization is embedded into the Community Land Model for the 
simulation of GPP and validated against 5 years of flux tower observations over irrigated and rainfed maize and soybean fields.

\section{Material and Methods}

\section{$136 \quad$ 2.1. Study site and measurements}

Flux tower observations, in-situ LAI and $\mathrm{Chl}_{1}$ measurements, and satellite-retrieved $\mathrm{Chl}_{1}$ from three sites (Ne1: $41.1645^{\circ} \mathrm{N}, 96.4766^{\circ} \mathrm{W}$; Ne2: $41.1649^{\circ} \mathrm{N}, 96.4701^{\circ} \mathrm{W} ; \mathrm{Ne} 3: 41.1797^{\circ} \mathrm{N}, 96.4396^{\circ} \mathrm{W}$ ) located at the University of Nebraska-Lincoln Agricultural Research and Development Center near Mead, Nebraska, were used in this study (Fig. 1). Ne1 has been planted with maize continuously since 2001, whereas Ne2 and $\mathrm{Ne} 3$ rotate between maize and soybean. Irrigation at fields $\mathrm{Ne} 1$ and $\mathrm{Ne} 2$ is managed by center pivot systems while $\mathrm{Ne} 3$ relies on rainfall. Irrigation at $\mathrm{Ne} 1$ and $\mathrm{Ne} 2$ approximately doubles the amount of water available when compared to precipitation alone (Kalfas et al., 2011) and the well-watered conditions resulted in sufficient soil moisture throughout the growing seasons over the five-year study period (2001 - 2005). All sites underwent application of herbicide, pesticide and $\mathrm{N}$ fertilizer in accordance with best management practices for optimizing crop yields and only the rainfed site (Ne3) experienced short periods of modest moisture stress (Verma et al., 2005). Further details of the sites and instrumentation are given in Verma et al., (2005).

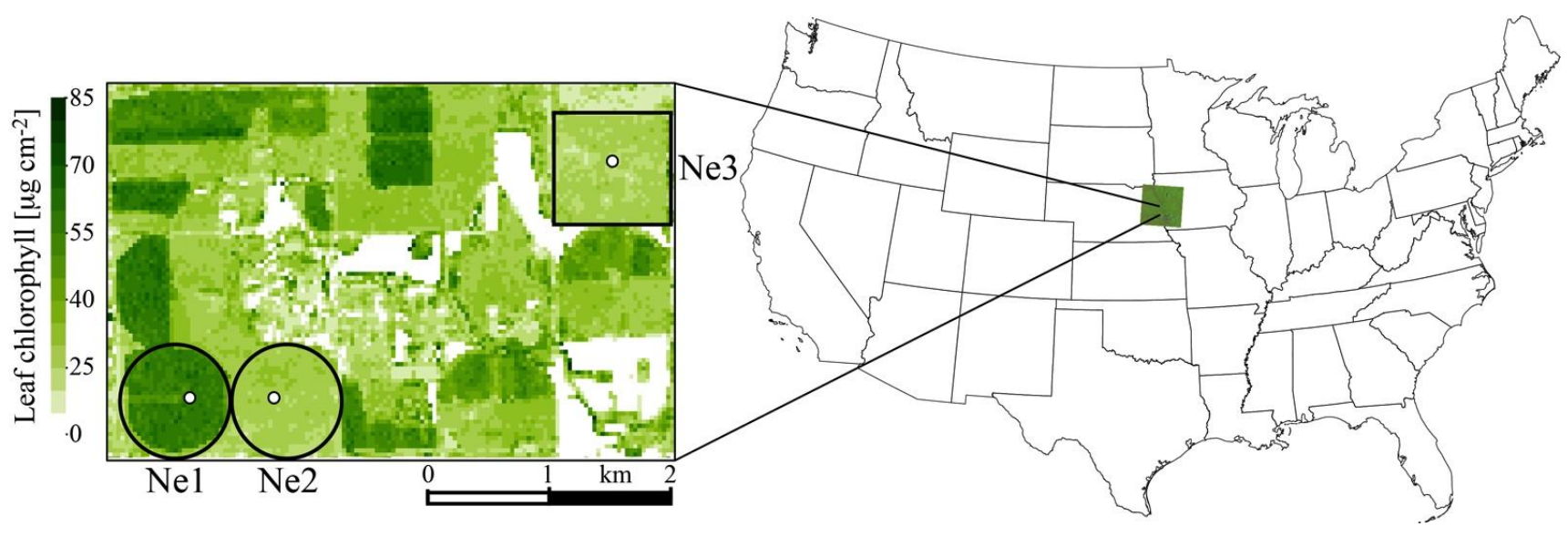

Fig. 1. Study area in Mead, Nebraska showing the locations of the three field sites under continuous irrigated maize (Ne1), irrigated maize-soybean (Ne2) and rainfed maize-soybean (Ne3). The white dots in each field represent the location of the flux towers. The map showcases retrievals of leaf chlorophyll content from Landsat data (day of year 196, 2002) using the REGFLEC model (section 2.3). 
In each field, micro-meteorological and eddy covariance instrumentation are deployed for continuous (half-hourly) measurements of standard meteorological variables and $\mathrm{CO}_{2}$, heat and water flux densities, as detailed in Verma et al. (2005) and Suyker and Verma (2010). Flux data are distributed under the fairuse policy in the Fluxnet - La Thuille synthesis dataset (http://www.fluxdata.org/, Agarwal et al., 2010). This study uses the half-hourly data, where the $\mathrm{CO}_{2}$ flux densities or net ecosystem $\mathrm{CO}_{2}$ exchange (NEE) measured by the EC system have been quality checked, gap-filled and partitioned into gross primary productivity (GPP) and ecosystem respiration (Re) based on a standardized technique and algorithm (Reichstein et al., 2005). In the derivation of GPP (GPP = NEE - Re), Re includes respiratory components from leaves, stems, boles and soil, determined based on nighttime NEE observations (where gross carbon uptake is assumed zero) and site-specific calibrated algorithms that define short-term temperature sensitivities of $\operatorname{Re}$ (Reichstein et al., 2005). Flux data are associated with random measurement errors ((Hollinger and Richardson, 2005; Post et al., 2015) and additional uncertainty (typically $<10 \%$ ) is introduced in the partitioning of NEE into GPP and TER (Desai et al., 2008). For the following analyses, $\mathrm{CO}_{2}$ taken up by the ecosystem is regarded as a positive flux.

Within each of the three fields, six small $(20 \mathrm{~m}$ x $20 \mathrm{~m}$ ) intensive measurements zones (IMZ) have been carefully established to represent the spatial variability in soil characteristics (e.g. moisture and organic matter content), topography and crop production potential in order to accurately upscale ground measurements to the whole-field level (Verma et al., 2005). Green LAI was determined from destructive samples of one-meter linear row sections in each IMZ, by multiplying the plant area (measured using a LI-3100, LI-COR, Inc., Lincoln, NE) with the plant population of each sampling location (Vina et al., 2011). Plots were sampled at 10- to 14-day intervals covering all phenological stages (green-up, reproductive and senescence stages) and resulting green LAI measurements have a reported mean standard error less than $0.15 \mathrm{~m}^{2} \mathrm{~m}^{-2}$ (Guindin-Garcia et al., 2012). Fraction of green leaves (fg) was derived from the destructive measurements of green and total LAI. $\mathrm{Chl}_{1}$ was estimated non-destructively based on reflectance measurements of ear or collar leaf in maize and upper canopy leaves in soybean, collected approximately twice a week within the six IMZs using a spectroradiometer equipped with a leaf clip, as described in Gitelson et al. (2005). $\mathrm{Chl}_{1}$ determined analytically in the lab was related to the red edge chlorophyll index $\left(\mathrm{CI}_{\text {red edge }}=\left(\mathrm{R}_{\text {nir }} / \mathrm{R}_{\text {rededge }}\right)-1\right)$ for the determination of linear regression coefficients (Ciganda et al., 2009) and the derived $\mathrm{Chl}_{1}$ vs. $\mathrm{CI}_{\text {rededge }}$ relationship was used to retrieve $\mathrm{Chl}_{1}$ of each leaf. The linear model allowed $\mathrm{Chl}_{1}$ estimation in both species, with an RMSD of less than $6 \square \mathrm{g} \mathrm{cm}^{-2}$ in the $\mathrm{Chl}_{1}$ range from $\sim 1-90 \square \mathrm{g} \mathrm{cm}^{-2}$ (Gitelson et al., 2005). LAI and $\mathrm{Chl}_{1}$ data at the six IMZs were areaweighted averaged to obtain field-wide representative values (Gitelson et al., 2003b). Since predominantly green leaves were sampled for $\mathrm{Chl}_{1}$ determination, estimates of total $\mathrm{Chl}_{1}$ averaging both 
green and senescent leaf material were calculated by multiplication with the field-wide estimates of fg. These estimates of $\mathrm{Chl}_{1}$ were used as input to CLM.

Given the large size of the fields and the central location of the towers (Fig. 4) the source areas (based on the two-dimensional footprint model by $\mathrm{Li}$ et al., 2008) contributing $90 \%$ of the measured $\mathrm{CO}_{2}$ fluxes were typically well within the field boundaries (not shown). The field-wide $\mathrm{Chl}_{1}$ and LAI estimates have been shown to be provide a good representation of the measured tower fluxes over the growing seasons (Gitelson et al., 2006b).

\subsection{Semi-mechanistic link between $\mathrm{Chl}_{l}$ and $\mathrm{V}_{\max }^{25}$}

Houborg et al. (2013) justified and outlined a semi-mechanistic formulation for linking $\mathrm{Chl}_{1}$ to the maximum rate of carboxylation at $25^{\circ} \mathrm{C}\left(V_{\max }^{25}\right)$, which assumes a linear relationship between $\mathrm{Chl}_{1}$ and leaf nitrogen $(\mathrm{N})$, and is given as:

$V_{\text {max }}^{25}=c_{0} \cdot K_{\text {cat }}^{25} \cdot F_{L N R} \cdot N=c_{0} \cdot K_{c a t}^{25} \cdot F_{L N R} \cdot\left(a \cdot C h l_{l}+b\right)$

Eq. 1

where $K_{\text {cat }}^{25}$ is the catalytic Rubisco turnover rate at $25^{\circ} \mathrm{C}, F_{L N R}$ is the fraction of leaf nitrogen in Rubisco, $a$ and $b$ are the slope and y-intercept of the linear regression and $c_{0}$ is a conversion factor given as 7/5500 (Houborg et al., 2013). Generalized relationships for $\mathrm{C}_{3}$ and $\mathrm{C}_{4}$ were established in Houborg et al. (2013). Here we perform an extensive literature synthesis to investigate the variability and correlation of interlinkages between $\mathrm{Chl}_{1}, \mathrm{~N}$, Rubisco and $V_{\max }^{25}$ within species utilizing the $\mathrm{C}_{3}$ and $\mathrm{C}_{4}$ photosynthetic pathways, in order to derive robust relationships for integrating estimates of $\mathrm{Chl}_{1}$ into the coupled photosynthesis-conductance scheme (Section 2.4).

The compilation of $\mathrm{N}-\mathrm{Chl}_{1}$ and Rubisco - N relationships (see Section 3.1) focuses on common agricultural crops such as wheat, rice, spinach, tobacco, barley, soybean, common bean, maize and sorghum. $F_{L N R}$, required as input to Eq. 1 , is derived from linear regression coefficients $\left(a_{l}\right.$ and $\left.b_{l}\right)$ for Rubisco versus $\mathrm{N}$ according to:

$F_{L N R}=\left(a_{1}+b_{1} / N\right) \cdot 0.16 / 14.0067 \cdot 10^{3}$

Eq. 2

where the fraction $0.16 / 14.0067$ converts from Rubisco protein to $\mathrm{N}$ content in mole units $\left[\mathrm{mol}_{\mathrm{N}} / \mathrm{g}_{\mathrm{Rub}}\right]$. With this information along with reported values of $K_{\text {cat }}^{25}$, crop-specific $V_{\text {max }}^{25} \operatorname{versus} \mathrm{Chl}_{1}$ relationships can be established based on Eq. 1. The results are presented and discussed in Section 3.1. 


\subsection{Satellite-based leaf chlorophyll dataset}

215

Satellite-based $\mathrm{Chl}_{1}$ were retrieved from Landsat time-series data using the Regularized Canopy 217 Reflectance (REGFLEC) model as detailed in Houborg et al. (2015) and briefly summarized below. REGFLEC represents a canopy radiative transfer model inversion system for translating at-sensor radiance observations into maps of $\mathrm{Chl}_{1}$ and LAI. It does this through use of a fully integrated system of leaf optical (PROSPECT; Jacquemoud and Baret, 1990; Feret et al., 2008) and radiative transfer models (SAIL: Verhoef, 1984; 6S: Vermote et al., 1997) and careful attention to confounding factors in spectrumtrait relations (Houborg et al., 2015). Acknowledging that universal vegetation index (VI) relationships do not exist, as reflectance spectra depend on complex interactions of many internal and external factors (Baret, 1991), REGFLEC attempts to establish a suite of predictive VI relationships, which depend on view and illumination geometry, crop class, phenological stage, soil background and atmospheric conditions. Given the ill-posed nature of model inversions resulting in non-unique solutions (Combal et al., 2002), REGFLEC embeds novel spatio-temporal regularization strategies (i.e. model constraints) and image-based ancillary information in an effort to increase the robustness and accuracy of retrieved properties, without relying on impractical site-specific calibration.

A total of 30 Landsat-5 TM and Landsat-7 ETM+ images (between DOY 161 and 255) were acquired over the studied fields to capture the variability in vegetation states (as described by $\mathrm{Chl}_{1}$ ) over the growing seasons for the $2001-2005$ study period. In preparation for the vegetation retrievals, all scenes were first automatically co-registered, resized (the Mead field sites are located in the center of a selected scene subset of 1136 x 523 pixels), corrected for cloud contamination and atmospherically corrected using spatially distributed information on atmospheric state parameters (e.g. aerosol optical depth, total precipitable water and total ozone) acquired from satellite data as detailed in Houborg et al. (2015). Yearspecific land cover maps were generated by REGFLEC based on seasonal differences in phenology, inferred from ancillary downscaled MODIS LAI time-series (Houborg et al., 2015) and Cropland Data Layer products for Nebraska. $\mathrm{LAI}$ and $\mathrm{Chl}_{1}$ were mapped within the functionally different vegetated land cover classes using a suite of relevant VI relationships determined by a multi-step look-up-table based inversion approach without local calibration and with attention to spatio-temporal differences in confounding (e.g. leaf structure, canopy architecture and soil background) factors. The performance of the REGFLEC-based $\mathrm{Chl}_{1}$ dataset in reproducing the dynamics of the in-situ measured $\mathrm{Chl}_{1}$ was described by a root-mean-square-deviation (RMSD) of $8.42 \mu \mathrm{g} \mathrm{cm}^{-2}$ and relative RMSD of $19 \%$, demonstrating reasonable capacity to reproduce crop-specific seasonal and interannual variability in $\mathrm{Chl}_{1}$ within irrigated and rainfed maize and soybean fields (Houborg et al. 2015). 
For integration into CLM and subsequent validation of simulated GPP against flux tower observations, the Landsat-based $\mathrm{Chl}_{1}$ retrievals were extracted within field-wide rectangles fitted to each site (540 $\mathrm{m} \mathrm{x}$ $540 \mathrm{~m}$ for all sites) and averaged to produce a single value of $\mathrm{Chl}_{1}$ for each field. This is consistent with the area-weighted averaging approach adopted for the in-situ measurements (Section 2.1). Between 5-7 Landsat scenes distributed over the growing season were acquired each year, with the retrievals linearly interpolated between acquisitions to reproduce daily variability. Satellite retrievals of $\mathrm{Chl}_{1}$ are highly uncertain for sparse vegetative covers, as it is difficult to separate the relatively small leaf contribution from the total signal (comprising leaf, canopy and soil contributions) (Houborg et al., 2015). Therefore, pixels during the green-up stage with an LAI $<1$ (as retrieved by REGFLEC) were assigned the pixelcorresponding $\mathrm{Chl}_{1}$ values from the nearest subsequent acquisition with vegetation densities above the LAI threshold.

\subsection{Community Land Model}

262

263

264

The Community Land Model version 4 (CLM4.0; http://www.cesm.ucar.edu/models/ccsm4.0/clm/) was used for simulating Gross Primary Productivity (GPP). A detailed description of the significant parameterization improvements and advances in process description over its predecessor CLM3.5 (Oleson et al., 2008) is provided in Oleson et al. (2010) and Lawrence et al. (2011). Leaf $\mathrm{CO}_{2}$ assimilation is modeled using a coupled photosynthesis-stomatal conductance model (see Bonan et al., 2011 for a complete list of equations) based on biochemical equations of $\mathrm{C}_{3}$ and $\mathrm{C}_{4}$ photosynthesis (Farquhar et al., 1980; Collatz et al., 1991; Collatz et al., 1992) and a semi-empirical model of stomatal conductance (Ball et al., 1987). In this framework, $\mathrm{CO}_{2}$ uptake is estimated as the minimum of the Rubisco limited, the electron transport (light) limited, and the export limited $\left(\mathrm{C}_{3}\right)$ or PEP-carboxylase limited $\left(\mathrm{C}_{4}\right)$ rates, which are solved separately for sunlit and shaded leaf fractions for canopy integration.

The maximum rate of carboxylation at $25{ }^{\circ} \mathrm{C}\left(V_{\max }^{25}\right)$ represents a critical input parameter that is prescribed for each plant functional type (PFT) based on time-invariant foliage nitrogen concentrations and specific leaf areas (Thornton and Zimmermann, 2007). The leaf photosynthetic rates are adjusted for nitrogen availability by multiplication of $V_{\max }^{25}$ with PFT-specific nitrogen availability factors derived from a simulation with the CLM carbon-nitrogen (CN) biochemistry model (Bonan et al. 2011). In addition, photoperiod-induced seasonality in leaf photosynthetic capacity may be considered by multiplication with a day-length factor (Bonan et al., 2011) that allows $V_{m a x}^{25}$ to retrieve its theoretical maximum on the summer solstice and gradually decline towards autumn (Bauerle et al., 2012; Houborg et 
al., 2013). The CN biochemistry model can be applied for a fully prognostic treatment of leaf area, vegetation and soil carbon pools, and nitrogen available for photosynthesis (Lawrence et al., 2011). However, in this study the so-called satellite phenology version (CLM4.0-SP) is utilized with leaf area index (LAI) prescribed from observations and $V_{\text {max }}^{25}$ either determined as mentioned above or derived from estimates of leaf chlorophyll (see Section 2.2).

\subsubsection{Updated model parameterization scheme}

Variations in $\mathrm{CO}_{2}$ assimilation scheme and model parameterization may significantly impact simulations of GPP (Chen et al., 2011). Bonan et al. (2011) provided an updated formulation and parameterization of the CLM4.0 leaf photosynthesis-conductance model to account for advances since its original implementation, including consideration of co-limitation of leaf photosynthetic rates, revised parameters for Rubisco kinetics and temperature dependencies and updated formulations of electron transportlimited, export-limited and $\mathrm{C}_{4}$ photosynthesis. These revisions substantially reduced leaf photosynthetic rates in both $\mathrm{C}_{3}$ and $\mathrm{C}_{4}$ plants compared to the original CLM4 parameterization, and improved the agreement with observationally based global flux fields upscaled from flux tower data. We adopt the Bonan et al. (2011) refined formulations of the photosynthesis-conductance model, but implement additional refinements and parameter updates for specific application to soybean $\left(\mathrm{C}_{3}\right)$ and maize $\left(\mathrm{C}_{4}\right)$ plants (Table A1) based on a literature synthesis as detailed in Appendix A.

\subsubsection{Model setup and validation}

In this study, single-point simulations of GPP were performed using the CLM with the revised parameterization scheme, forced with tower-based meteorology (solar radiation, air temperature and humidity, wind speed, precipitation, surface pressure) and in-situ based LAI. CLM was run with a fixed

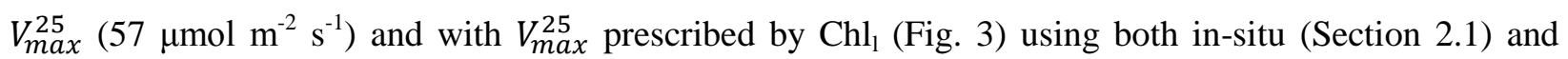
satellite-based $\mathrm{Chl}_{1}$ datasets (Section 2.3). The fixed value of $V_{\max }^{25}$ used here for both maize and soybean corresponds to the assigned CLM PFT-specific (crop) value not adjusted for N limitation (Bonan et al., 2011), which approximately represents the midpoint of parameter values used across a wide range of TBMs (Rogers, 2014).

While REGFLEC also outputs LAI, the in-situ based and destructively sampled LAI record was used in this analysis as it provides an accurate estimate of the true LAI at the studied fields and a stronger basis for evaluating the specific utility of $\mathrm{Chl}_{1}$ as a proxy for photosynthetic capacity. Although CLM allows for 
316 photoperiod-induced seasonality in $V_{\max }^{25}$ based on a daylength factor, this option was not invoked in these 317 analyses. Houborg et al. (2013) reported a minimal impact of this seasonal adjustment over a maize 318 growing season in Maryland, USA and argued that a more refined methodology should be implemented 319 to realistically account for photoperiod associated declines in photosynthetic capacity.

Hourly simulations of GPP were validated against flux tower observations by bin-averaging the data by hour over segmented series of 5 days. This is a common approach (Baldocchi et al., 2000), which serves to reduce the random measurement errors associated with the carbon flux observations (Moncrieff et al., 1996). Model performance was assessed using the Mean Bias Error (MBE), the Root-Mean-SquareDeviation (RSMD), the coefficient of determination $\left(r^{2}\right)$ and the coefficient of efficiency $(E) \cdot r^{2}$ is a traditional correlation-based metric to evaluate the goodness-of-fit of the model and it describes the proportion of the observed variance that can be explained by the model. $E$ has been described as an improvement over $r^{2}$ (Legates and McCabe, 1999) and varies from 1 (perfect fit) to $-\infty$, where negative values indicate that the observed mean is a better predictor than the model.

\section{Results and Discussion}

\section{1. $\mathrm{Chl}_{l}-\mathrm{V}_{\max }^{25}$ relationships}

Fig. 2a and 2b depict linear relationships between $\mathrm{Chl}_{1}$ and $\mathrm{N}$ reported in the literature for $\mathrm{C}_{3}$ and $\mathrm{C}_{4}$ species over different ranges of $\mathrm{Chl}_{1}$. The $\mathrm{C}_{3}$ data represent a compilation of data for wheat, rice, spinach, tobacco, barley, soybean and common bean (Evans, 1989; Maekawa and Kokubun, 2005; O'Neill et al., 1984; Seemann et al., 1987; Sudo et al., 2003; Theobald et al., 1998; Yamori et al., 2011). The two parameters are highly correlated, with values of $r^{2}$ ranging from 0.75 to 0.94 (Fig. 2a). Although significant differences in the slope and y-intercept of individual relationships are evident, the scattered points (each relationship is represented by three points; two at the extremes ( $\min$ and max) and one at the midpoint of the $\mathrm{Chl}_{1}$ range) can be reasonably approximated by a single regression with an $\mathrm{r}^{2}$ of 0.91 and a relative root-mean-square-deviation (RMSD) of $16 \%$ (Fig. 2a and Table 1). Robust linear relationships between $\mathrm{Chl}_{1}$ and $\mathrm{N}\left(\mathrm{r}^{2}=0.66-0.98\right)$ are also observed for $\mathrm{C}_{4}$ species (Fig. 2b) including grasses, weeds, 
b)

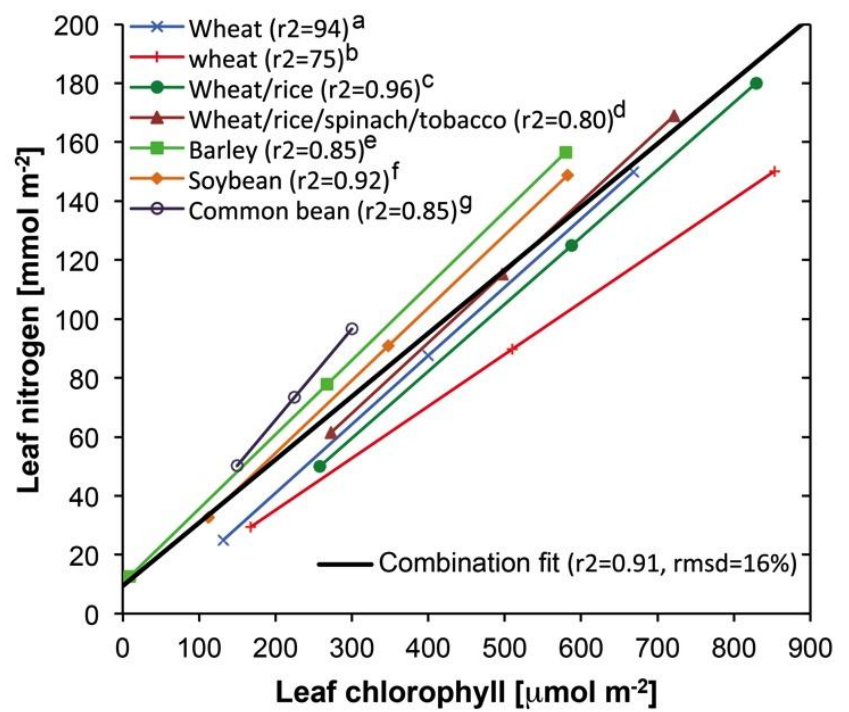

Fig. 2. (a) Linear regressions and observed ranges of leaf nitrogen versus leaf chlorophyll for various $\mathrm{C}_{3}$ species compiled from the literature. The goodness of fit $\left(\mathrm{r}^{2}\right)$ as reported in the source is provided for each regression. The regression coefficients of the linear model (thick black line) fitted to the scattered points (each relationship is represented by three points; one at each of the extremes and one at the midpoint of the $\mathrm{Chl}_{1}$ range) are given in Table 1. ${ }^{\mathrm{a}}$ Evans 1989; ${ }^{\mathrm{b}}$ Theobald et al., 1998; 'Sudo 2003; ' Yamori et al., 2011; e'O'Neill et al., 1984; ${ }^{\mathrm{f}}$ Maekawa and Kokubun 2005; ' ${ }^{\mathrm{g}}$ Seeman et al., 1987. (b) Similar to (a) but for $\mathrm{C}_{4}$ species. ${ }^{\mathrm{a}}$ Ghannoum et al., 2005; ${ }^{\mathrm{b}}$ Sage et al., 1987; ${ }^{\mathrm{c}}$ Osaki et al., 1995; ${ }^{\mathrm{d}}$ Schlemmer et al., 2013; ${ }^{\mathrm{C}}$ hao et al., 2003; ' Zhao et al., 2005.

a)

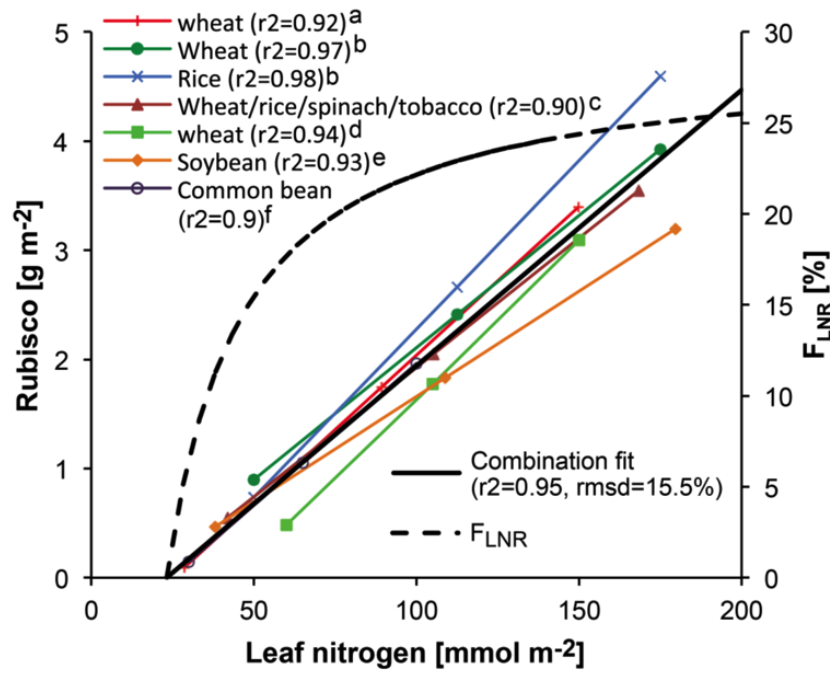

b)

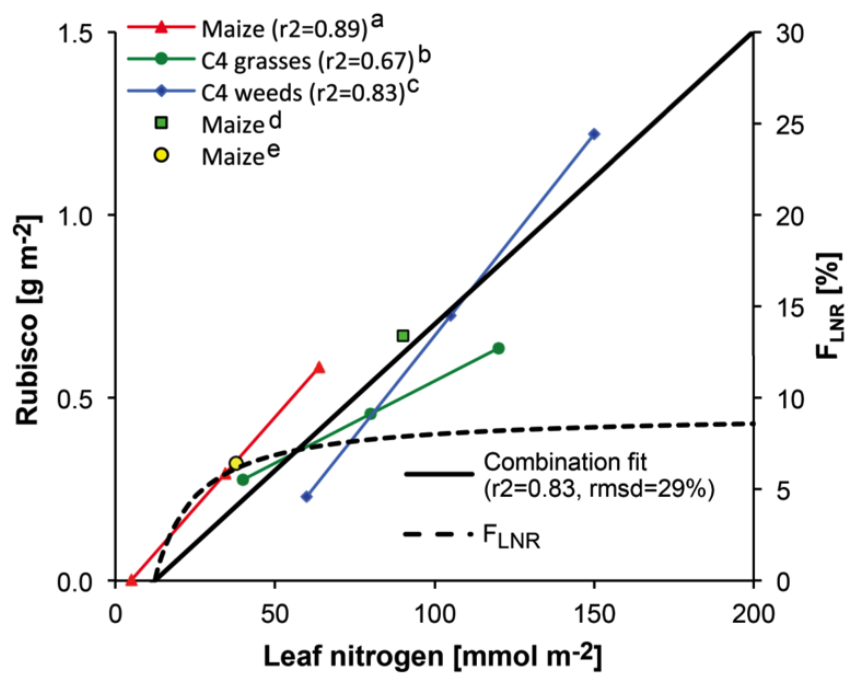

Fig. 3. (a) Linear regressions and observed ranges of leaf nitrogen versus Rubisco for various $\mathrm{C}_{3}$ species compiled from the literature. The goodness of fit $\left(\mathrm{r}^{2}\right)$ as reported in the source is provided for each regression. The regression coefficients of the linear model fitted to the scattered points are given in Table 1. The resulting \% of leaf nitrogen in Rubisco $\left(\mathrm{F}_{\mathrm{LNR}}\right)$ is depicted on the secondary axis. ${ }^{\mathrm{a}}$ Theobald et al., 1998; ' $\mathrm{S} u d o, 2003$; ${ }^{\mathrm{c}}$ Yamori et al., 2011; ${ }^{\mathrm{d}}$ Evans 1986; ${ }^{\mathrm{e}}$ Maekawa and Kokubun, 2005; ' Seemann et al., 1987. (b) Similar to (a) but for $\mathrm{C}_{4}$ species. ${ }^{\mathrm{a}}$ Osaki et al., 1995; ' $\mathrm{Ghannoum}$ et al., 2005; 'Sage et al., 1987; ' Makino et al., 2003; ' Schmidt and Edwards, 1981. 
Table 1. Linear regression coefficients $(y=a x+b)$ for Rubisco (Rub) versus leaf nitrogen $(N)$ and $N$ versus leaf chlorophyll $\left(\mathrm{Chl}_{1}\right)$ for $\mathrm{C}_{3}$ and $\mathrm{C}_{4}$ plant species obtained from the fitted line based on a literature review (Fig. 2 and 3). Regression coefficients for $V_{\max }^{25}$ versus $\mathrm{Chl}_{1}$ were derived based on Eq. 1 and depends on $K_{c a t}^{25}$ specification (Table 1). Rub is in $\left[\mathrm{g} \mathrm{m}^{-2}\right], \mathrm{N}$ is in $\left[\mathrm{mmol}_{\mathrm{N}} \mathrm{m}^{-2}\right], \mathrm{Chl}_{1}$ is in $\left[\mu \mathrm{mol}_{\mathrm{chl}} \mathrm{m}^{-2}\right]$ and $V_{\text {max }}^{25}$ is in $\left[\mu \mathrm{mol}_{\mathrm{CO} 2} \mathrm{~m}^{-2} \mathrm{~s}^{-1}\right]$, except where otherwise noted. In the transformation for calculating $\mathrm{F}_{\mathrm{LNR}}$, the fraction 0.16/14.0067 converts from Rubisco protein to $\mathrm{N}$ content in mole units $\left[\mathrm{mol}_{\mathrm{N}} \mathrm{g}_{\text {Rub }}{ }^{-1}\right.$. The conversion of chlorophyll units from $\left[\mu \mathrm{mol}_{\mathrm{chl}} \mathrm{m}^{-2}\right]$ to $\left[\mu \mathrm{g}_{\mathrm{chl}} \mathrm{cm}^{-2}\right]$ was performed by multiplication with the molecular mass of Chl $\left(\sim 896.8 \mu \mathrm{g} \mu \mathrm{mol}^{-1}\right.$ assuming a chlorophyll a/b ratio of 3.3; Makino et al., 2003) and division by $10^{4}$.

\begin{tabular}{|c|c|c|c|}
\hline & a (slope) & $\mathrm{b}(\mathrm{y}$-intercept $)$ & 353 \\
\hline \multicolumn{4}{|c|}{$\mathrm{N}$ versus $\mathrm{Chl}_{1}\left(\mathrm{~N}=\mathrm{aChl}_{1}+\mathrm{b}\right)$} \\
\hline $\mathrm{C}_{3}$ & $0.2143\left[\mathrm{mmol}_{\mathrm{N}} \mu \mathrm{mol}_{\mathrm{chl}^{-1}}{ }^{-1}\right]$ & $9.417\left[\mathrm{mmol}_{\mathrm{N}} \mathrm{m}^{-2}\right]$ & 354 \\
\hline $\mathrm{C}_{4}$ & $0.2139\left[\mathrm{mmol}_{\mathrm{N}} \mu \mathrm{mol}_{\mathrm{chl}}{ }^{-1}\right]$ & 0 & 355 \\
\hline \multicolumn{4}{|c|}{ Rubisco versus $N(\mathrm{Rub}=\mathrm{aN}+\mathrm{b})$} \\
\hline $\mathrm{C}_{3}$ & $2.527 \mathrm{e}^{-2}\left[\mathrm{~g}_{\text {Rub }} \mathrm{mmol}_{\mathrm{N}}^{-1}\right]$ & $-0.587\left[\mathrm{~g}_{\text {Rub }} \mathrm{m}^{-2}\right]$ & 356 \\
\hline $\mathrm{C}_{4}$ & $8.010 \mathrm{e}^{-3}\left[\mathrm{~g}_{\text {Rub }} \mathrm{mmol}_{\mathrm{N}}^{-1}\right]$ & $-0.100\left[g_{\text {Rub }} \mathrm{m}^{-2}\right]$ & \\
\hline \multicolumn{2}{|c|}{$F_{L N R}=(a+b / N) \cdot 0.16 / 14.0067 \cdot 10^{3}$} & & 357 \\
\hline \multicolumn{4}{|c|}{$V_{\max }^{25}$ versus $\mathrm{Chl}_{1}\left(V_{\max }^{25}=\mathrm{aChl}_{1}+\mathrm{b}\right)$} \\
\hline $\mathrm{C}_{3}\left(\mathrm{Chl}_{1}\right.$ in $\left.\left[\mu \mathrm{mol} \mathrm{m}{ }^{-2}\right]\right)$ & $7.878 \mathrm{e}^{-2} \cdot K_{\text {cat }}^{25}\left[\mu \mathrm{mol}_{\mathrm{CO} 2} \mu \mathrm{mol}_{\mathrm{Chl}}{ }^{-1}\right]$ & \multicolumn{2}{|c|}{$-5.074 \cdot K_{c a t}^{25}\left[\mu \mathrm{mol}_{\mathrm{CO} 2} \mathrm{~m}^{-2} \mathbf{3} 5 \mathrm{~g}\right.$} \\
\hline $\mathrm{C}_{3}\left(\mathrm{Chl}_{1}\right.$ in $\left.\left[\mu \mathrm{g} \mathrm{cm}^{-2}\right]\right)$ & $8.776 \mathrm{e}^{-1} \cdot K_{\text {cat }}^{25}\left[\mu \mathrm{mol}_{\mathrm{CO} 2} \mu \mathrm{g}_{\mathrm{Ch}}{ }^{-1}\right]$ & \multicolumn{2}{|c|}{$-5.074 \cdot K_{c a t}^{25}\left[\mu \mathrm{mol}_{\mathrm{CO} 2} \mathrm{~m}^{-2} \mathrm{~s}^{-1}\right]$} \\
\hline $\mathrm{C}_{4}\left(\mathrm{Chl}_{1}\right.$ in $\left.\left[\mu \mathrm{mol} \mathrm{m}{ }^{-2}\right]\right)$ & $2.492 \mathrm{e}^{-2} \cdot K_{c a t}^{25}\left[\mu \mathrm{mol}_{\mathrm{CO} 2} \mu \mathrm{mol}_{\mathrm{Chl}}{ }^{-1}\right]$ & \multicolumn{2}{|c|}{$-1.454 \cdot K_{c a t}^{25}\left[\mu \mathrm{mol}_{\mathrm{CO} 2} \mathrm{~m}^{-2} 36 \rho\right.$} \\
\hline $\mathrm{C}_{4}\left(\mathrm{Chl}_{1}\right.$ in $\left.\left[\mu \mathrm{g} \mathrm{cm}^{-2}\right]\right)$ & $2.779 \mathrm{e}^{-1} \cdot K_{c a t}^{25}\left[\mu \mathrm{mol}_{\mathrm{CO} 2} \mu \mathrm{g}_{\mathrm{Ch}}{ }^{-1}\right]$ & \multicolumn{2}{|c|}{$-1.454 \cdot K_{c a t}^{25}\left[\mu \mathrm{mol}_{\mathrm{CO} 2} \mathrm{~m}^{-2} \mathrm{~s}^{-1}\right]$} \\
\hline
\end{tabular}

Table 2. Mean and standard deviations among reported values of the catalytic Rubisco turnover rate at $25^{\circ} \mathrm{C}\left(K_{\text {cat }}^{25}\right)$ for important agricultural crops. If not originally reported at $25^{\circ} \mathrm{C}$, the values were normalized to $25^{\circ} \mathrm{C}$ assuming an energy of activation of 61 and $56 \mathrm{KJ} \mathrm{mol}^{-1}$, representing group averages from a variety of $\mathrm{C} 3$ and $\mathrm{C} 4$ plants, respectively (Sage 2002) (i.e. $K_{c a t}^{T l}=K_{c a t}^{25} \exp \left(\left[E\left(T_{l}-298\right)\right] /\left[298 R_{\text {gas }} T_{l}\right]\right)$, where $\mathrm{T}_{1}$ is leaf temperature $\left({ }^{\circ} \mathrm{K}\right)$ and $\mathrm{R}_{\text {gas }}$ is the universal gas constant (8.3143 units)

\begin{tabular}{|c|c|c|}
\hline Plant species & $K_{\text {cat }}^{25}\left(\mathrm{~s}^{-1}\right)$ & Sources \\
\hline \multicolumn{3}{|l|}{ C3 plants } \\
\hline Soybean & $1.99 \pm 0.05$ & Seemann et al. (1984), Vu et al. (1997), Reid et al. (1997) \\
\hline Common bean & $2.26 \pm 0.53$ & Seemann et al. (1984), Sharkey et al. (1991), Sage et al. (1990) \\
\hline Cotton & $2.01 \pm 0.33$ & Seemann et al. (1984), Sage (2002) \\
\hline Rice & $1.82 \pm 0.18$ & $\begin{array}{l}\text { Sage (2002), Vu et al. (1997), Makino et al. (1994), Ishikawa et al. (2011), Makino et } \\
\text { al. (1988), Morita et al. (2014) }\end{array}$ \\
\hline Wheat & $3.01 \pm 0.43$ & $\begin{array}{l}\text { Sicher and Bunce (1997), Rintamaki et al. (1988), Theobald et al. (1998), Seemann et } \\
\text { al. (1984), Cousins et al. (2010), Evans and Seemann (1984), Makino et al. (1988) }\end{array}$ \\
\hline Barley & $3.49 \pm 0.57$ & Sicher and Bunce (1997) \\
\hline Tobacco & $3.21 \pm 0.36$ & Von Caemmerer (2000), Ruuska et al. (1998) \\
\hline \multicolumn{3}{|l|}{ C4 plants } \\
\hline Maize & $4.04 \pm 0.57$ & Seemann et al. (1984), Kubien et al. (2008), Cousins et al. (2010), Wang et al. (2008) \\
\hline Sorghum & $4.51 \pm 0.59$ & Seemann et al. (1984), Ishikawa et al. (2011) \\
\hline
\end{tabular}


maize and sorghum (Ghannoum et al., 2005; Osaki et al., 1995; Sage et al., 1987; Schlemmer et al., 2013; Zhao et al., 2005, 2003). Similar to the $\mathrm{C}_{3}$ species, the linear combination regression for $\mathrm{C}_{4}$ plants describes the variability with an $\mathrm{r}^{2}$ of 0.93 and a relative RMSD of $14 \%$ (Fig. 2b).

A relationship between Rubisco content and $\mathrm{N}$ must be established for deriving $F_{L N R}$ (Eq. 2), which is required as input to Eq. 1. The synthesized relationships for $\mathrm{C}_{3}$ (Fig. 3a) and $\mathrm{C}_{4}$ (Fig. 3b) species demonstrate strong linear correlations and the importance of distinguishing species utilizing differing photosynthetic pathways; the $\mathrm{C}_{4}$ species have a maximum $F_{L N R}$ on the order of $8 \%$ whereas the $\mathrm{C}_{3}$ species have around 3 times as much Rubisco at equivalent N (Fig. 3b). Since the linear Rubisco versus N relationship has a negative y-intercept, $F_{L N R}$ increases with increasing $\mathrm{N}$, which results in a curvilinear $F_{L N R}$ response.

The kinetic constants of Rubisco for $\mathrm{C}_{4}$ species have been shown to differ from those of $\mathrm{C}_{3}$ species (Seemann et al., 1984) and a literature review of reported values of the catalytic Rubisco turnover rate at $25^{\circ} \mathrm{C}\left(K_{c a t}^{25}\right)$ for important agricultural crops (Table 2) suggest higher values for $\mathrm{C}_{4}$ species. The higher turnover rates are partly compensated for by lower Rubisco contents (Fig. 3). There is also significant variation between different $\mathrm{C}_{3}$ species, with plants from cool habitats (e.g. wheat, barley) tending to have higher turnover rates than plants from warmer habitats (e.g. soybean, cotton, rice) (Table 2). $V_{\text {max }}^{25}$ versus $\mathrm{Chl}_{1}$ relationships, established based on the synthesized $\mathrm{C}_{3}$ and $\mathrm{C}_{4}$-specific regression coefficients (Table 1), are highly dependent upon the specification of $K_{\text {cat }}^{25}$ (Fig. 4). For comparison, the relationship between $V_{\max }^{25}$ and $\mathrm{N}$ established for $\mathrm{C}_{3}$ crops and based on a dataset of leaf traits and model inversions of the maximum photosynthetic rate (Kattge et al., 2009) is also plotted in Fig. 4 using the $C_{3}$ specific linear regression coefficients for converting from $\mathrm{Chl}_{1}$ to $\mathrm{N}$ (Table 1). An obvious difference is the positive intercept, which implies a positive carboxylation capacity for zero $\mathrm{Chl}_{\mathrm{l}}$, whereas the relationships resulting from this study predict a zero carboxylation capacity for $\mathrm{Chl}_{1}$ of approximately $5 \mu \mathrm{g} \mathrm{cm}^{-2}$ (Fig. 3). The linear models derived in this study are based on observations covering a wide range in $\mathrm{N}$ and $\mathrm{Chl}_{1}$ (Fig. 2), including $\mathrm{N}$ values below the physiological range used in Kattge et al. (2009), resulting in a better constrained linear model over this range.

\subsection{Field- and satellite-based vegetation time-series data}

Model simulations of GPP over maize and soybean were based on the growing season vegetation data displayed in Fig. 5 including field measured (a) green LAI ( $\mathrm{LAI}_{\mathrm{g}}$ ) and (b) $\mathrm{Chl}_{\mathrm{l}}$, as well as (c) satellite retrieved $\mathrm{Chl}_{1}$. The displayed 5-day segmented time-series are based on the field-wide aggregated values (Section 2.1 and 2.3) encompassing all available data points from both irrigated ( $\mathrm{Ne} 1$ and $\mathrm{Ne} 2)$ and 


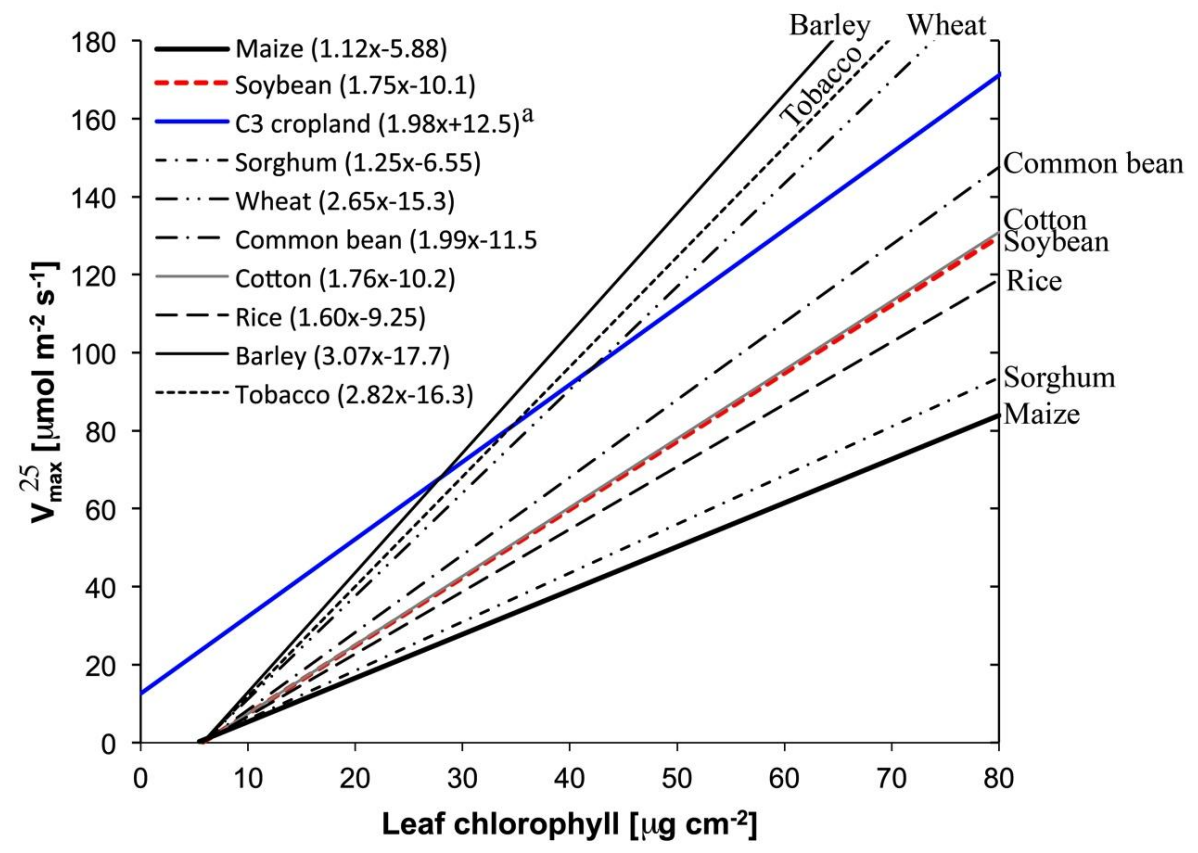

Fig. 4. $V_{\text {max }}^{25}$ versus $\mathrm{Chl}_{1}$ relationships for important agricultural $\mathrm{C}_{3}$ and $\mathrm{C}_{4}$ crops, established based on Eq. 1 using $\mathrm{N}$ versus $\mathrm{Chl}_{1}$ and Rubisco versus $\mathrm{N}$ regression coefficients from Table 1 and values of

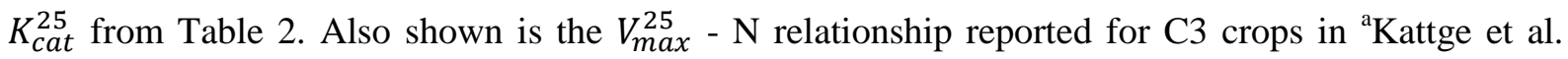
(2009).

rainfed (Ne3) field sites for five growing seasons (2001 - 2005). The grey area above and below the vegetation time-series represents \pm 1 standard deviation (SD) of the averaged data points. The bulk of the data relates to maize, with data available for a total of 11 site-years (i.e. Ne1: 2001 - 2005; Ne2 and Ne3: 2001, 2003, 2005). Soybean was only cultivated at Ne2 and Ne3 in 2002 and 2004 (i.e. 4 site-years).

The general phenology of $\mathrm{LAI}_{\mathrm{g}}$ in maize is characterized by a rapid green-up reaching a peak $\mathrm{LAI}_{\mathrm{g}}$ of $\sim 5$ around DOY 200, followed by a relatively constant $\mathrm{LAI}_{\mathrm{g}}$ during the reproductive stage before gradually declining through the senescence stage. The soybean LAI phenology is different, with a longer green-up stage, a lower maximum $\mathrm{LAI}_{\mathrm{g}}(\sim 4)$ and a more rapid decline during the senescence stage. As a result of contrasting leaf structures and functionally different species type (i.e. $\mathrm{C}_{3}$ versus $\mathrm{C}_{4}$ ), $\mathrm{Chl}_{1}$ levels in maize and soybean are significantly different, as can be seen from the field-based time-series data that record an average maize $\mathrm{Chl}_{1}$ during the reproductive stage on the order of $55-60 \mu \mathrm{g} \mathrm{cm}{ }^{-2}$, compared to $\sim 30 \mu \mathrm{g} \mathrm{cm}^{-2}$ in soybean (Fig. 5b). $\mathrm{Chl}_{1}$ in both maize and soybean is characterized by a steady decline during the senescence stage, dropping to 20 and $12 \mu \mathrm{g} \mathrm{cm}^{-2}$, respectively (Fig. 5b). In maize, the high SD $( \pm 10.9 \mu \mathrm{g}$ $\mathrm{cm}^{-2}$ on average) is an indication of significant seasonal, inter-annual and inter-field variability caused by different environmental conditions, phenology and agricultural management practices. Despite a higher 

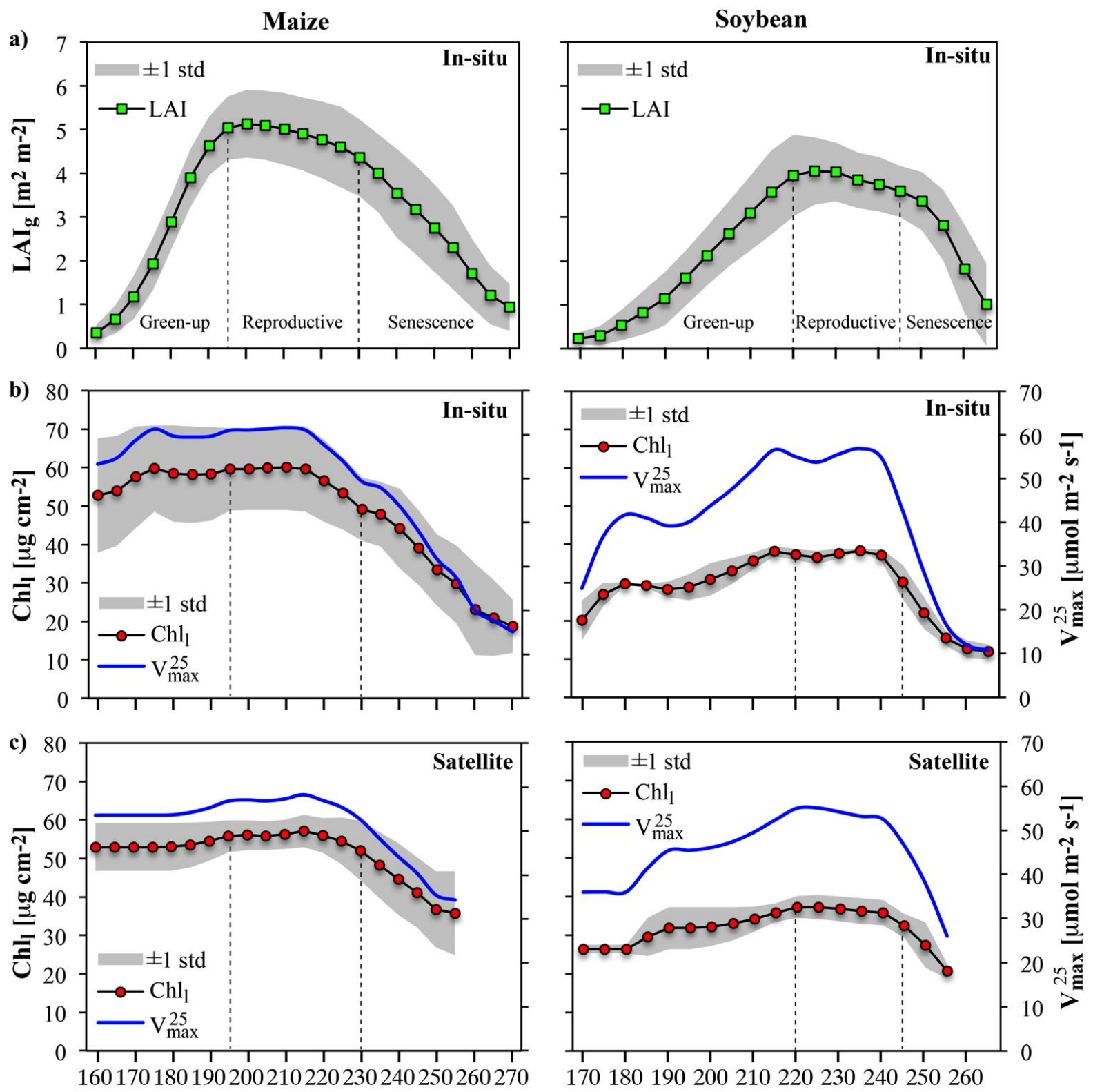

Day of year

Fig. 5. Site (Ne1, Ne2, Ne3) and year (2001 - 2005) averaged time-series of the available in-situ measured (a) green LAI and (b) $\mathrm{Chl}_{1}$ and satellite retrieved (c) $\mathrm{Chl}_{1}$ for maize and soybean fields at Mead, Nebraska. The grey area represent \pm 1 standard deviation of the data and reflects the degree of intra and inter-field variability over the five year period $(2001-2005)$. Note that the maize and soybean time-series were based on a total of 11 (Ne1: 2001 - 2005; $\mathrm{Ne} 2$ and Ne3: 2001, 2003, 2005) and 4 ( $\mathrm{Ne} 2$ and $\mathrm{Ne} 3: 2002,2004)$ site-years, respectively, except that in-situ $\mathrm{Chl}_{1}$ was not available in 2004 (Ne2 and Ne3). In (b) and (c) the resulting values of $V_{\max }^{25}$ calculated from the averaged $\mathrm{Chl}_{1}$ time-series (see Table 1) are plotted on the secondary y-axis. (b) and (c) plot the field-averaged $\mathrm{Chl}_{1}$ encompassing both green and senescent leaf material. 
frequency of the in-situ samplings (twice a week) compared to the satellite retrievals ( $5-7$ acquisitions per growing season), the seasonal trends and magnitudes of the satellite-based $\mathrm{Ch}_{1}$ are similar to the insitu records for both maize and soybean (Fig. 5c), although the SD of the satellite-based $\mathrm{Ch}_{1}$ data in maize is substantially lower $\left(6.4 \mu \mathrm{g} \mathrm{cm}^{-2}\right)$.

Despite significant differences in $\mathrm{Chl}_{1}$ levels in maize and soybean, values of $V_{\max }^{25}$ calculated from the synthesized $\mathrm{Chl}_{1}$ time-series data using the derived regression coefficients specific to maize and soybean (Fig. 3), are characterized by similar ranges varying from $15-62 \mu \mathrm{mol} \mathrm{m}{ }^{-2} \mathrm{~s}^{-1}$ and $10-58 \mu \mathrm{mol} \mathrm{m}^{-2} \mathrm{~s}^{-1}$, respectively for the field measured data (Fig. 5b) and from $35-59 \mu \mathrm{mol} \mathrm{m} \mathrm{m}^{-2}$ and $27-56 \mu \mathrm{mol} \mathrm{m}^{-2} \mathrm{~s}^{-1}$, respectively for the satellite-based data (Fig. 5c). The maximum $V_{\max }^{25}$ values are close to the fixed value of $V_{\text {max }}^{25}$ adopted for cropland in the CLM $\left(57 \mu \mathrm{mol} \mathrm{m} \mathrm{m}^{-2} \mathrm{~s}^{-1}\right.$; not adjusted for $\mathrm{N}$ availability).

\subsection{Model sensitivity to changes in $V_{\max }$ and parameterizations}

Physical realism is a key requirement of TBMs in order to reliably model GPP. However, improved process understanding and descriptions typically contributed to increased model complexity. The potential downside of enhanced complexity is the inherent uncertainty associated with specifying the typically large number of model parameters with acceptable accuracy.

Fig. 6 compares simulations of GPP based on the model parameterizations used in Bonan et al. (2011) (S1) to model simulations using the updated parameterization scheme (S2) (see Table A1 for a complete list of model parameters used in the two schemes). Hourly simulations were generated from model runs over the 2002 maize and soybean growing seasons and subsequently bin-averaged by hour to produce a single diurnal curve of GPP, which is representative of a wide range of environmental and phenological conditions. For the same $V_{\max }^{25}$ specification (i.e. $50 \mu \mathrm{mol} \mathrm{m}^{-2} \mathrm{~s}^{-1}$ ), the $\mathrm{S} 1$ simulations overestimate the $\mathrm{S} 2$ simulations (maize) during midday with approximately $9 \mu \mathrm{mol} \mathrm{m}^{-2} \mathrm{~s}^{-1}$ (Fig. 6a), corresponding to $\sim 20 \%$. This difference is largely attributed to 1 ) the modeling of the light-limited rate for $\mathrm{C}_{4}$ plants in $\mathrm{S} 1$ as a function of the quantum yield with no maximum limit, instead of making it dependent on the electron transport rate (S2) (Appendix A) and 2) the adopted parameter values for the quantum yields and potential rate of electron transport (Table A1). Large discrepancies occur in the GPP estimates between S1 and S2 in soybean (Fig. 6a). The high temperature inhibition functions adopted in S1 initiates thermal breakdown 448 of metabolic processes above approximately $30^{\circ} \mathrm{C}$, which causes significant reductions in GPP during the 449 midday hours (Fig. 6a). These tendencies are not supported by the observed GPP as evidenced by an $r^{2}$ of 0.78 compared to 0.95 based on S2 model simulations that assume an optimum temperature of $V_{\text {max }}$ of 
Maize

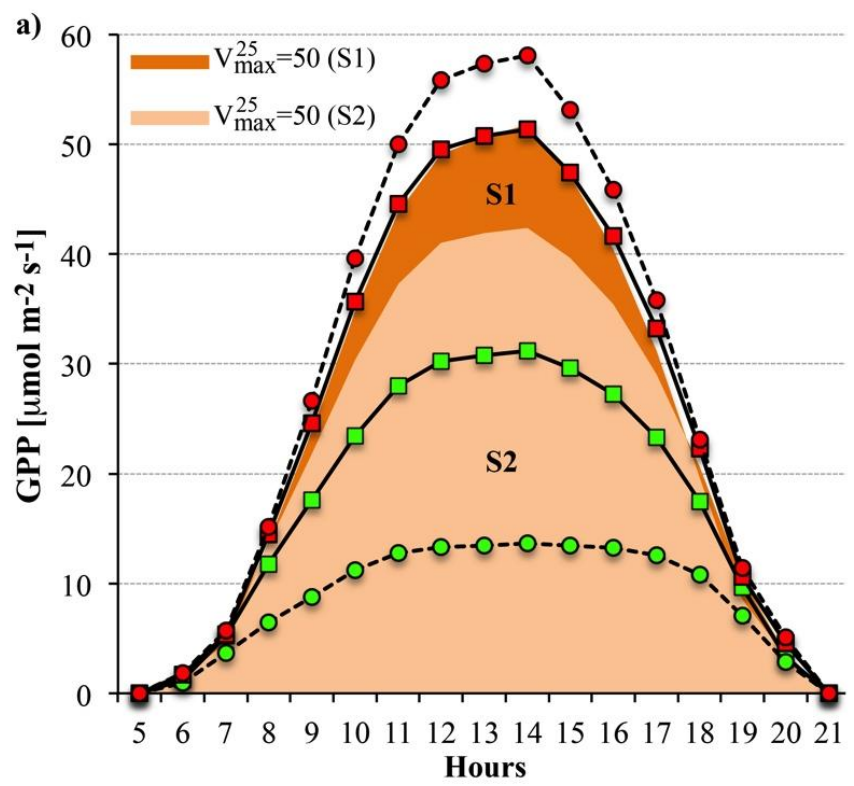

b)

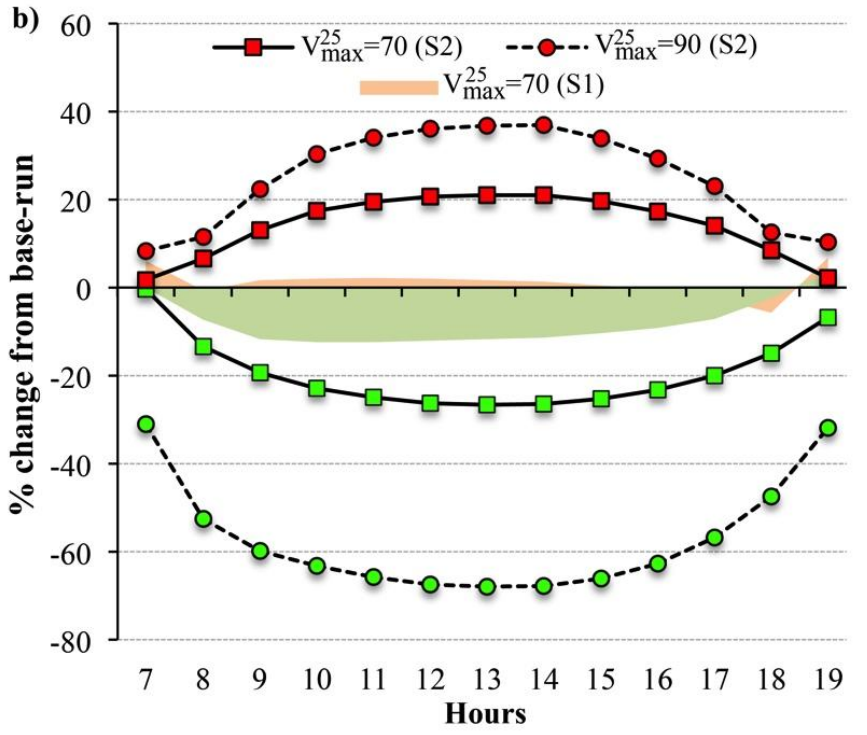

Soybean
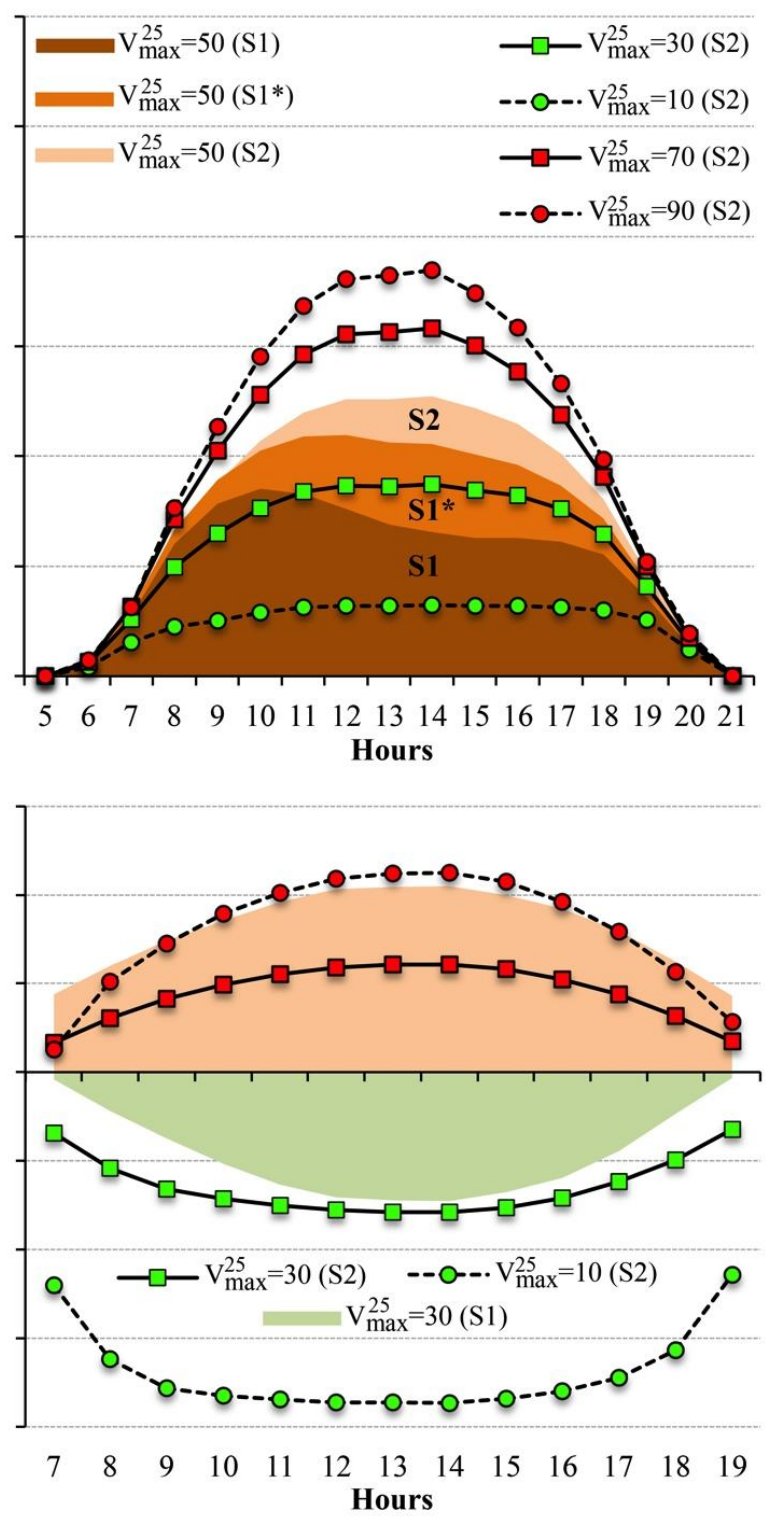

Fig. 6. (a) Model simulations of GPP parameterized according to Bonan et al. (2011) (S1) and the revised scheme from this study (S2). Hourly simulations over the full duration of the 2002 growing season have been bin-averaged by hour. (b) Sensitivity of GPP to variations in $\mathrm{V}_{\max }$ displaying the \% change in GPP from the base run $\left(\mathrm{V}_{\max }=50 \mu \mathrm{mol} \mathrm{m} \mathrm{s}^{-2} \mathrm{~s}^{-1}\right.$.

$45141.9^{\circ} \mathrm{C}$ (Appendix A). If the high temperature stress functions are disabled in S1 (i.e. S1*), agreement 452 with the observations improve considerably $\left(r^{2}=0.93\right)$ and the $S 1$ estimates become more comparable to 453 the S2 estimates (Fig. 6a). This suggests a high adaptation ability of soybean to high temperatures. 454 Clearly, the type and form of the temperature response functions are critically important and models 
should be parameterized to better account for significant variations in the temperature responses of photosynthetic capacities between plants at leaf temperatures above $30^{\circ} \mathrm{C}$ (Leuning, 2002).

Additional CLM model runs were undertaken with input of different $V_{\max }^{25}$ values (i.e. 10, 30, 50, 70, 90 for $\mathrm{S} 2$ and 30, 50, 70 for $\mathrm{S} 1$ ) to assess the sensitivity of GPP to variations in the leaf photosynthetic capacity. For S2, the diurnal GPP levels resulting from the five different $V_{\max }^{25}$ inputs are reported in Fig. 6a, with Fig. 6b showing the corresponding $\%$ change in GPP from the nominal run $\left(V_{\max }^{25}=50 \mu \mathrm{mol} \mathrm{m}^{-2} \mathrm{~s}^{-}\right.$ ${ }^{1}$ ). Changing $V_{\max }^{25}$ from 50 to $70 \mu \mathrm{mol} \mathrm{m} \mathrm{m}^{-2} \mathrm{~s}^{-1}$ translates to a $21 \%$ (maize) and $24 \%$ (soybean) increase in GPP at noon, whereas a decrease from 50 to $30 \mu \mathrm{mol} \mathrm{m} \mathrm{m}^{-2} \mathrm{~s}^{-1}$ causes a $26 \%$ (maize) and $31 \%$ (soybean) reduction in GPP at noon (Fig. 6b). As expected, the strongest impact of $V_{\max }^{25}$ occurs during the midday hours when irradiance is high and photosynthesis is primarily limited by the Rubisco capacity (von Caemmerer, 2000).

The sensitivity results using S2 highlight the critical need for appropriate specification of $V_{\max }^{25}$ in order to reduce uncertainties of model predicted GPP (Rogers, 2014; Zaehle, 2005). Interestingly, the sensitivity results based on $\mathrm{S} 1$ suggest significantly reduced model sensitivity to $\pm 20 \mu \mathrm{mol} \mathrm{m}^{-2} \mathrm{~s}^{-1}$ variations in $V_{\text {max }}^{25}$ in maize (Fig. 6b). As mentioned above, the calculation of $\mathrm{C}_{4}$ photosynthesis differs between the two parameterization schemes and whereas $V_{\max }^{25}$ directly controls light-limited assimilation in S2 through the potential rate of electron transport (Appendix A), the quantum yield, which is parameterized independently of $V_{\text {max }}^{25}$, is the dominant control in $\mathrm{S} 1$. Thus depending on the value used for the quantum yield (0.05 mol mol-1 used here) and the degree of co-limitation imposed between light-limited and

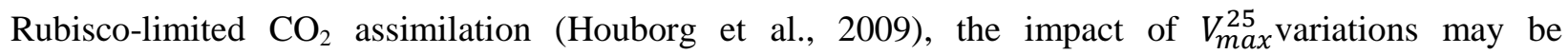
significantly subdued when using S1.

\subsection{Leaf chlorophyll constraint on GPP}

Fig. 7a displays time-series maps of $V_{\max }^{25}$ in the vicinity of the Mead study sites during the year 2002, derived from Landsat-based $\mathrm{Chl}_{1}$ retrievals using land cover specific $V_{\text {max }}^{25}-\mathrm{Chl}_{1}$ relationships. These were established on the basis of a semi-mechanistic link between $\mathrm{Chl}_{1}, \mathrm{~N}$, Rubisco and $V_{\max }^{25}$ and parameterized based on an extensive review of the experimental literature (Section 3.1). During 2002, field site Ne1 was planted with continuously irrigated maize while sites $\mathrm{Ne} 2$ and $\mathrm{Ne} 3$ were planted with irrigated and rainfed soybean, respectively. Seasonal, intra-field and inter-field variability can be clearly identified, with the most significant change occurring between DOY 220 and 252 when the phenological stage shifts from 

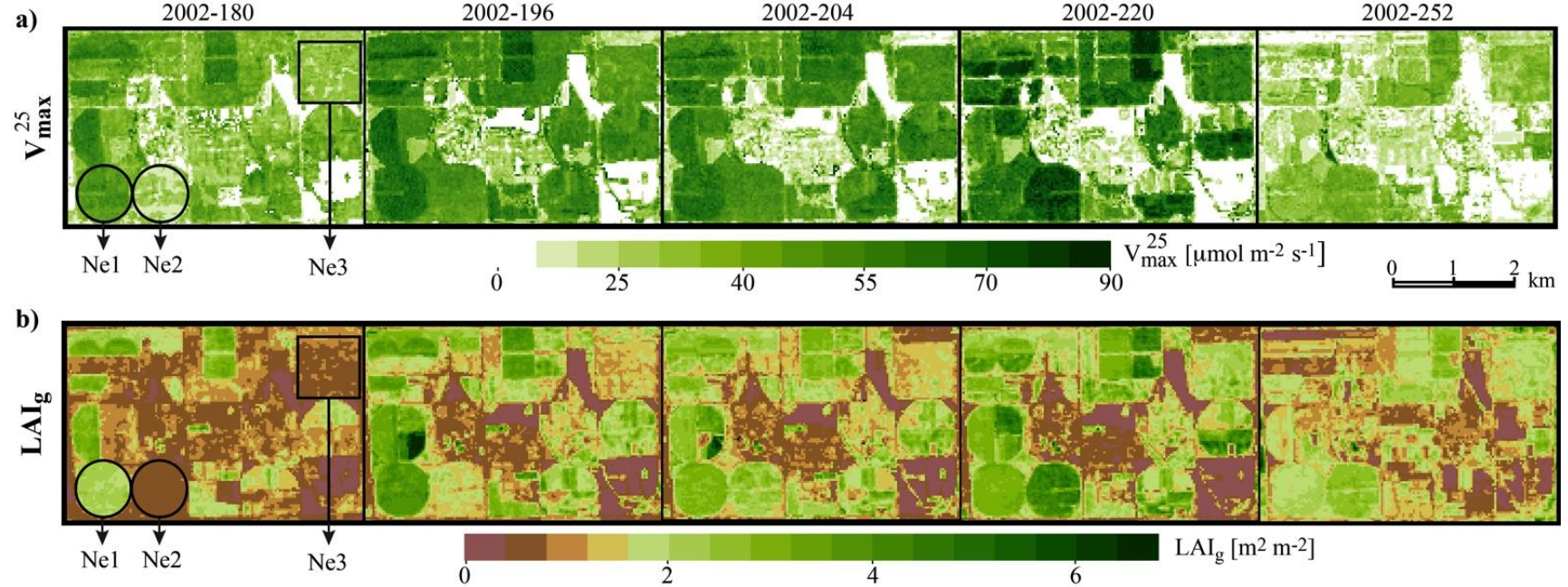

c)
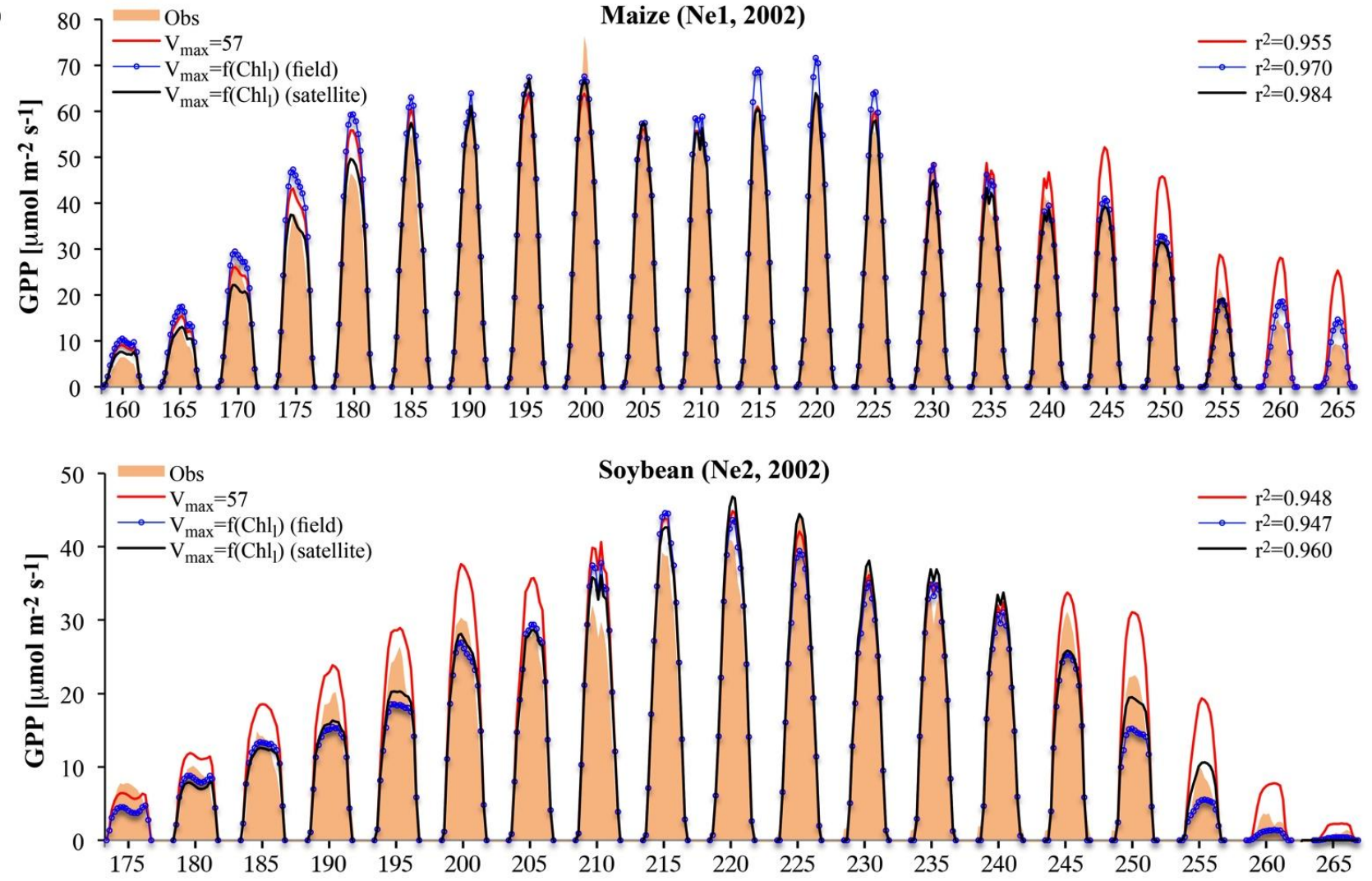

Fig. 7. (a) Maps of $V_{\max }^{25}$ over the field sites during the 2002 growing season, derived from satellitebased estimates of $\mathrm{Chl}_{1}$ using the established regression equations (Table 1). (b) Associated maps of green LAI jointly retrieved with $\mathrm{Chl}_{1}$ as part of the REGFLEC retrieval system. (c) Comparison of flux tower observed GPP to single-point simulations of GPP using a fixed $V_{\text {max }}^{25}$ and $V_{\text {max }}^{25}$ dictated by variations in field-measured and satellite-retrieved $\mathrm{Chl}_{1}$. Each diurnal segment represents flux data averaged by hour over 5-day intervals. 
reproductive to senescence (Fig. 5). Fig. 7b displays associated maps of green LAI jointly retrieved with $\mathrm{Chl}_{1}$ as part of the REGFLEC retrieval system. This LAI dataset was not used in the present study, as field measured green LAI was used to force the single-point model simulations of GPP at the three field sites. However, future applications of CLM will include spatially distributed (satellite-based) inputs of both LAI and $\mathrm{Chl}_{1}$ for facilitating model application over spatial and temporal domains.

Fig. 7c compares hourly 5-day bin-averaged flux tower observed GPP to single-point simulations of GPP for maize (Ne1) and soybean (Ne2) during 2002, using a seasonally fixed $V_{\max }^{25}$ and $V_{\max }^{25}$ dictated by variations in field-measured and satellite-retrieved $\mathrm{Chl}_{1}$. In maize, the $\mathrm{Chl}_{1}$-based parameterizations of $V_{\max }^{25}$ cause a significant increase in the coefficient of determination $\left(\mathrm{r}^{2}\right)$ relative to using a fixed $V_{\max }^{25}$. Improvements are particularly evident during the late reproductive and senescence stages, where $\mathrm{Chl}_{1}$ gradually declines (Fig. 5 and Fig. 7a) and where the use of a fixed $V_{\text {max }}^{25}$ leads to substantial model overestimations. A similar tendency is evident for soybean in addition to significant overestimation during the green-up phase using a fixed $V_{\max }^{25}$. However, in both maize and soybean, the fixed value of 57 $\mu \mathrm{mol} \mathrm{m} \mathrm{m}^{-2} \mathrm{~s}^{-1}$ provides an excellent match with observations during most of the reproductive stage (Fig. 7c).

Fig. 8 synthesizes data from all sites and years and displays the temporal behavior of model performance over maize and soybean growing seasons based on quantitative statistical metrics including the mean bias error, MBE (Fig. 8a), coefficient of efficiency, E (Fig. 8b) and root-mean-square deviation, RMSD (Fig. 8c). Time-period specific MBE, $E$ and RMSD were calculated using all available GPP simulations within the displayed DOY intervals based on a fixed $V_{\max }^{25}$ and $V_{\max }^{25}$ derived from satellite (S) and field-based (F) $\mathrm{Chl}_{1}$.

The field sites were managed according to best practice, using herbicide and pesticide applications, fertilizer and irrigation (except $\mathrm{Ne} 3$ ) for optimizing crop yields and resulting in minimal crop stress due to soil moisture and nutrient limitations over the studied years (Verma et al., 2005). As a result, the model with a fixed $V_{\max }^{25}$ performs best during peak LAI in the first half of the reproductive stage, whereas the late reproductive and senescence stage is where the largest effect of the $\mathrm{Chl}_{1}$ constraint on GPP in both maize and soybean (Fig. 8) is seen. GPP simulations using a fixed $V_{\max }^{25}$ substantially overestimate observations during this period, with the MBE and RMSD in maize and soybean reaching peak values of 6.5 and $9.3 \mu \mathrm{mol} \mathrm{m} \mathrm{s}^{-2}$ and 5 and $5.1 \mu \mathrm{mol} \mathrm{m} \mathrm{m}^{-2} \mathrm{~s}^{-1}$, respectively. In addition, $E$ drops markedly to levels close to zero (Fig. 8b), suggesting that the observed mean is as good a predictor as the model (Legates and McCabe, 1999). Simulations constrained by $\mathrm{Chl}_{1}$ (either satellite or field-based) on the other hand, 
Maize
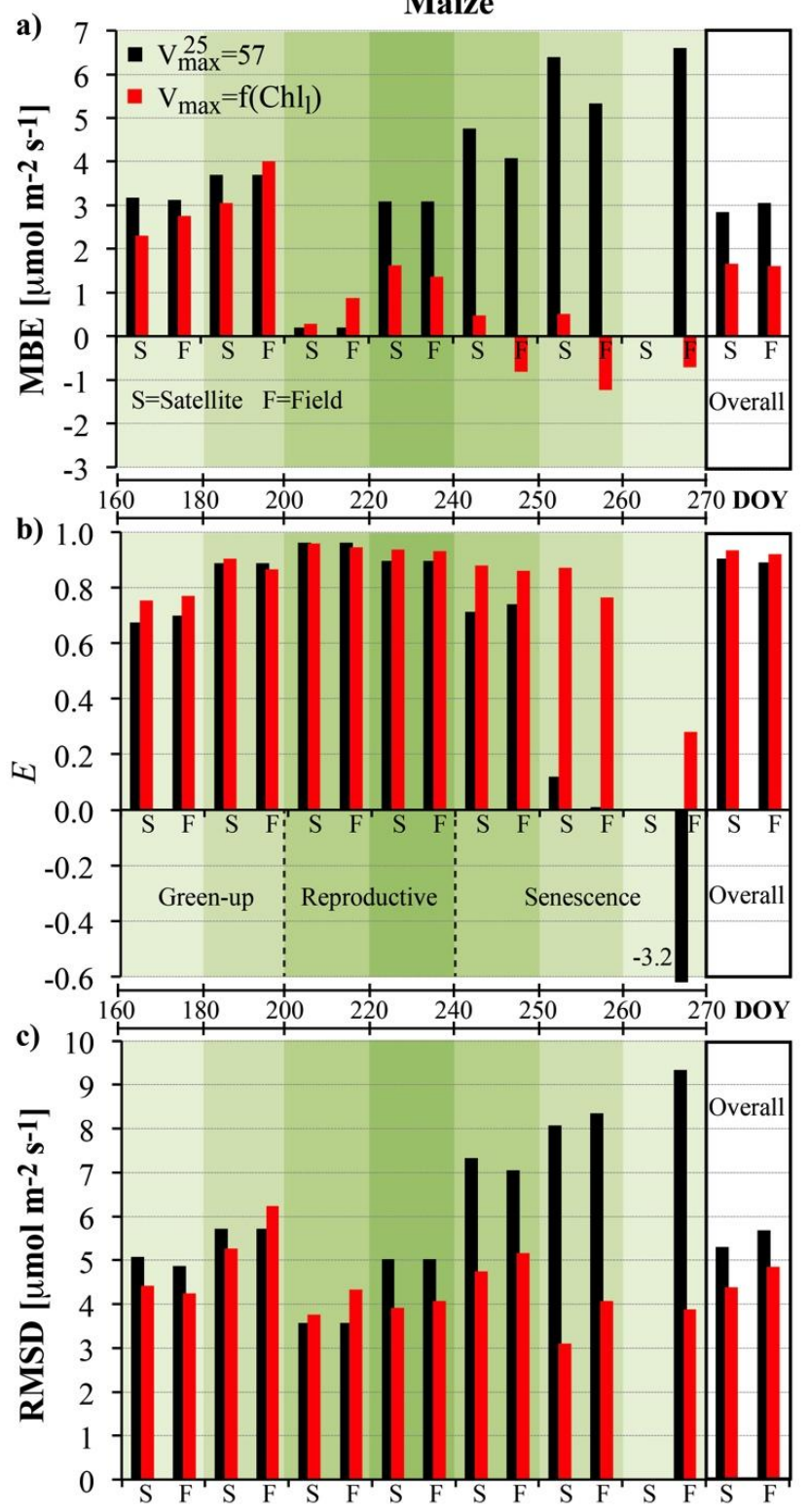

\section{Soybean}
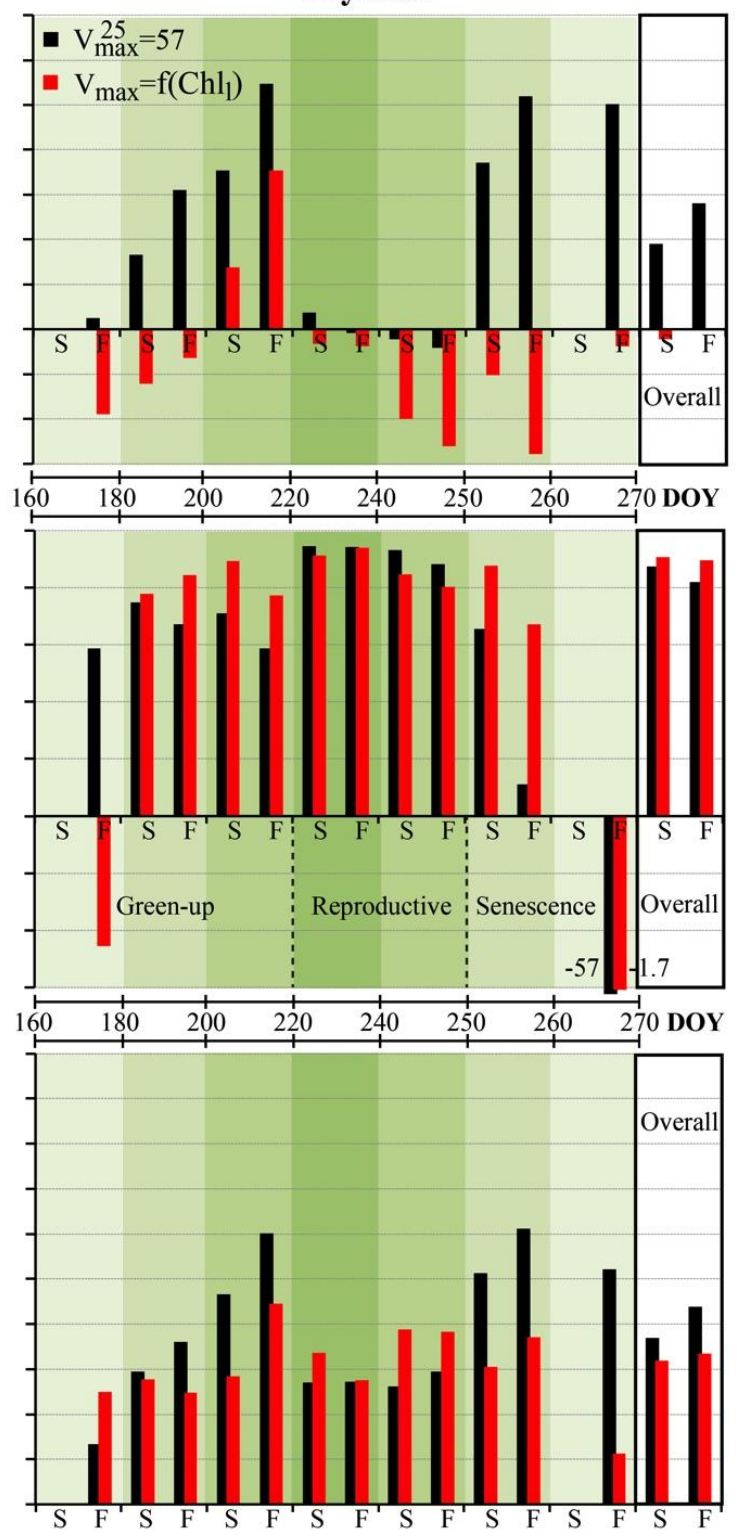

Fig. 8. Compilation of $\mathrm{CO}_{2}$ flux data from all sites and years, displaying temporal behaviour of model performance within periods of 10 to 20 days in terms of the (a) mean bias error (MBE), (b) coefficient of efficiency $(E)$ and (c) root-mean-square-deviation (RMSD). 
Table 3. Quantitative statistic measures of the overall performance of CLM in estimating daytime hourly GPP over the full growing seasons for maize when using $V_{\max }^{25}$ fixed at $57 \mu \mathrm{mol} \mathrm{m} \mathrm{m}^{-2} \mathrm{~s}^{-1}$ and $V_{\max }^{25}$ dictated by variations in satellite and field measured $\mathrm{Chl}_{1}$. $\mathrm{N}$ is the number of samples, $\mathrm{O}$ is the mean of the flux tower observations, RMSD is the root-mean-square difference between model estimates and measurements, MBE is the mean bias error (if positive the model overestimates measurements), $\mathrm{r}^{2}$ is the coefficient of determination, and $E$ is the coefficient of efficiency. The upper and lower $95 \%$ confidence levels are given for the fixed $V_{\text {max }}^{25}$ results. On the basis of these, bolded figures indicates a significant increase in $\mathrm{r}^{2}$ relative to the $V_{\text {max }}^{25}=57$ runs at the $5 \%$ significance level. O, RMSD and MBE have units of $\mu \mathrm{mol} \mathrm{m} \mathrm{m}^{-2}$.

\begin{tabular}{lllllll}
\hline Simulation (maize) & $\mathrm{N}$ & $\mathrm{O}$ & $\mathrm{MBE}$ & $\mathrm{RMSD}$ & $\mathrm{r}^{2}$ & $E$ \\
\hline Satellite-based Chl & & & & & & \\
$V_{\max }^{25}=57$ & 2739 & 26.6 & 2.85 & 5.30 & $0.942(0.937-0.946)$ & 0.91 \\
$V_{\max }^{25}=\mathrm{f}\left(\mathrm{Chl}_{1}\right)$ & 2739 & 26.6 & 1.66 & 4.38 & $\mathbf{0 . 9 5 2}$ & 0.94 \\
Field measured Chl $l_{l}$ & & & & & & \\
$V_{\max }^{25}=57$ & 3151 & 24.6 & 3.06 & 5.68 & $0.931(0.926-0.935)$ & 0.89 \\
$V_{\max }^{25}=\mathrm{f}\left(\mathrm{Chl}_{1}\right)$ & 3151 & 24.6 & 1.61 & 4.85 & $\mathbf{0 . 9 4 3}$ & 0.92 \\
\hline
\end{tabular}

Table 4. Like Table 3 but for soybean.

\begin{tabular}{lllllll}
\hline Simulation (soyb) & $\mathrm{N}$ & $\mathrm{O}$ & $\mathrm{MBE}$ & $\mathrm{RMSD}$ & $\mathrm{r}^{2}$ & $E$ \\
\hline Satellite-based Chl & & & & & & \\
$V_{\max }^{25}=57$ & 831 & 17.6 & 1.90 & 3.68 & $0.91(0.90-0.92)$ & 0.87 \\
$V_{\max }^{25}=\mathrm{f}\left(\mathrm{Chl}_{1}\right)$ & 831 & 17.6 & -0.22 & 3.18 & 0.91 & 0.91 \\
Field measured Chl $l_{l}$ & & & & & & \\
$V_{\max }^{25}=57$ & 496 & 16.1 & 2.80 & 4.38 & $0.90(0.88-0.91)$ & 0.82 \\
$V_{\max }^{25}=\mathrm{f}\left(\mathrm{Chl}_{1}\right)$ & 496 & 16.1 & 0.00 & 3.33 & 0.90 & 0.90 \\
\hline
\end{tabular}

In terms of overall model performance (over the full multi-year growing seasons), the use of time-series $\mathrm{Chl}_{1}$ data as a proxy for variations in photosynthetic capacity leads to reductions in model bias (Fig. 8a) and RMSD (Fig. 8c) and increases in $E$ (Fig. 8b) in both maize and soybean. Improvements in overall model performance are most evident for maize, where the increase in $\mathrm{r}^{2}$ relative to the fixed $V_{\max }^{25}$ run is statistically significant at the $5 \%$ level for both satellite and field-based $\mathrm{Chl}_{1}$ (Table 3). Although the $\mathrm{r}^{2}$ statistics for soybean are not significantly different between the fixed and seasonally variable $V_{\max }^{25}$ runs, the satellite-based $\mathrm{Chl}_{1}$ constraint results in $E$ increasing from 0.87 to 0.91 , a substantial bias reduction from 1.9 to $-0.22 \mu \mathrm{mol} \mathrm{m} \mathrm{s}^{-2} \mathrm{~s}^{-1}$ and the RMSD decreasing from 3.68 to $3.18 \mu \mathrm{mol} \mathrm{m}^{-2} \mathrm{~s}^{-1}$ (Table 4), which is similar to the performance level obtained using the field measured $\mathrm{Chl}_{1}$ record (Table 4). In maize, the results based on the satellite-retrieved $\mathrm{Chl}_{1}$ constitute a slight improvement over model runs informed by the field-measured $\mathrm{Ch}_{1}$ data (Table 3 and Fig. 8). This suggests that there is utility of satellite-based $\mathrm{Ch}_{1}$ 
as an observational model constraint despite significant challenges associated with the retrieval of leaf biochemistry and relatively high retrieval uncertainties (Houborg et al., 2015).

552

\subsection{Potentials and limitations of $\mathrm{Chl}_{1}$ as a proxy for $\mathrm{V}_{\max }^{25}$}

The use of best management practices for optimizing crop yields resulted in optimal field conditions (in terms of water and nutrient availability) during most of the green-up and reproductive stage, as reflected by relatively constant levels of $\mathrm{Chl}_{1}$ during this period at the studied fields. Model runs using a seasonally fixed value of $V_{\max }^{25}$ (57) compared favorably against flux observations during the optimal growth conditions around peak LAI, but resulted in substantial positive model biases towards the end of the growing season. Accordingly, the largest benefit of using $\mathrm{Chl}_{1}$ as a model constraint on GPP was reported during the late reproductive and senescence stages, where reductions in chlorophyll occurred due to leaf aging and increasing leaf senescence. Houborg et al. (2013) demonstrated the benefit of using $\mathrm{Chl}_{1}$ to down-regulate $V_{\max }^{25}$ during a maize growing season exposed to severe environmental conditions and resulting in pronounced water and $\mathrm{N}$-limited conditions. Obviously, the value of $\mathrm{Chl}_{1}$ as a model constraint will be maximized in fields exposed to longer periods of temperature, moisture and nutrient stress.

$\mathrm{Chl}_{1}$ was translated into $V_{\max }^{25}$ for integration into the leaf-photosynthesis-conductance scheme of the CLM using crop-specific linear regressions based on an extensive literature review and synthesis. Results demonstrated the utility of $\mathrm{Chl}_{1}$ as a proxy for spatio-temporal variations in leaf photosynthetic capacity in irrigated and rainfed maize and soybean fields. TBMs typically assign a single value of $V_{\text {max }}^{25}$ to each broadly defined PFT and at best distinguish between $\mathrm{C}_{3}$ and $\mathrm{C}_{4}$ croplands (Rogers, 2014). However, the $V_{\text {max }}^{25}-\mathrm{Chl}_{1}$ regressions derived in this study indicate a large variability within the $\mathrm{C}_{3}$ cropland PFT (Fig. $3)$, primarily as a result of significant variations in reported values of the Rubisco turnover rate $\left(K_{c a t}^{25}\right)$ between species (Table 2), which serves as a key input to the semi-mechanistic equation linking $\mathrm{Chl}_{1}$ and $V_{\max }^{25}$ (Eq. 1). In light of the large sensitivity of modeled GPP to changes in $V_{\max }^{25}$ (Fig. 6) and significant within PFT variability in $V_{\max }^{25}$ as a result of changes in crop type, photosynthetic pathway and $\mathrm{N}$ availability (Kattge et al., 2009), the need to constrain this parameter is obvious and the reliability of model simulations of GPP in space and time depends heavily on an observationally-based scheme to accurately account for these variations in $V_{\text {max }}^{25}$. 
$\mathrm{Chl}_{1}$ serves as a strong candidate as an operational proxy for $\mathrm{N}$ (Homolová et al., 2013) and thus $V_{\max }^{25}$, but a successful utilization of earth observation-based $\mathrm{Chl}_{1}$ information within land-surface modeling schemes ultimately depends on (1) the validity of established regressions between $V_{\text {max }}^{25}$, Rubisco enzyme kinetics, $\mathrm{N}$, and $\mathrm{Chl}_{1},(2)$ the achievable $\mathrm{Chl}_{1}$ retrieval accuracy and sampling frequency, and (3) the physical realism of the modeling scheme and validity of model parameterizations, as further elaborated on below.

The outlined semi-mechanistic formulation assumes strong correlations between $\mathrm{N}$ and $\mathrm{Chl}_{1}$ and between Rubisco and $\mathrm{N}$, which were generally observed in the compiled studies on cropland species $\left(\mathrm{r}^{2}\right.$ ranging from $0.69-0.98$ and $0.67-97$, respectively). Lower $\mathrm{N}-\mathrm{Chl}_{1}$ correlations have occasionally been reported for coniferous canopies and certain shrub, graminoide and herb species (see Homolová et al., 2013 for a review). While $\mathrm{N}-\mathrm{Chl}_{1}$ and Rubisco $-\mathrm{N}$ relationships are species-specific to some extent (Fig. 2 and 3), distinguishing between $\mathrm{C}_{3}$ and $\mathrm{C}_{4}$ photosynthetic pathways appear to capture most of the variability within the studied cropland species. Another potential source of variation includes interrelated features of light environment and leaf dry mass per area during vegetation growth (Hallik et al., 2012; Wright et al., 2004), which may significantly alter these correlative relationships, as exemplified by a higher $\mathrm{Chl}_{1}$ to $\mathrm{N}$ ratio of plants grown in low light environments (Evans, 1989; Hallik et al., 2009). However remote sensors in the visible spectrum only see the top-most canopy layers (Ciganda et al.,, 2012), predominantly exposed to high irradiances, and the adopted relationships between $\mathrm{Chl}_{\mathrm{l}}, \mathrm{N}$ and $V_{\max }^{25}$ were established to reflect that. The impact of light acclimation on the vertical profile of photosynthetic capacity is often considered in TBMs on the basis of the upper canopy estimate, through assumptions on $\mathrm{N}$ distribution and allocation within the canopy and division into sunlit and shaded leaf components (e.g. de Pury and Farquhar, 1997; Thornton and Zimmermann, 2007). The specification of $K_{c a t}^{25}$ may represent the largest uncertainty (Rogers, 2014), as a small adjustment in this parameter will significantly alter the intercept and slope of the $V_{\max }^{25}-\mathrm{Chl}_{1}$ relationship (Table 1). Importantly, the compilation of $K_{c a t}^{25}$ values for common agricultural crops (Table 2) indicates that parameterization at the broad PFT-level (i.e. $\mathrm{C}_{3}$ and $\mathrm{C}_{4}$ ) may not be sufficient for capturing the variability between species. While uncertainties inevitably exist, the use of $\mathrm{Chl}_{1}$ for constraining $V_{\max }^{25}$ provides a physically meaningful mechanism for accounting for variations in photosynthetic potentials within and between agricultural plant species, thereby reducing some of the large uncertainties associated with the use of prescribed PFTspecific values.

Despite a relatively high Landsat-based $\mathrm{Chl}_{1}$ retrieval error (19\%) (Section 2.3), the improvement in GPP predictability is similar between the two $\mathrm{Chl}_{1}$ datasets, and the high temporal frequency of the in-situ $\mathrm{Chl}_{1}$ ( $\sim 3$ days) provides no clear advantage over the $5-7$ Landsat acquisitions available during each growing 
season (DOY 160 to 260). However, in many situations the average 20-day gap may not be sufficient to capture the effect of intermittent moisture and nutrient stress and accurately record the onset and duration of stress events and initiation of chlorophyll reductions. Improving the sampling frequency of satelliteretrieved $\mathrm{Chl}_{1}$ could prove critical for properly resolving time and space-varying dynamics in leaf photosynthetic capacity, and may be achieved by employing a data fusion approach to exploit multi-scale and multi-sensor data streams synergistically (Gao et al., 2006; Houborg et al., 2013).

Once operational, the pair of Sentinel-2 satellites will have a revisit capability of 5 days and combined with high spatial resolution $(10-20 \mathrm{~m})$ and bands in the red-edge region with enhanced sensitivity to $\mathrm{Ch}_{1}$ (Clevers and Gitelson, 2013; Dash and Curran, 2007; Shlemmer et al., 2013) are likely to provide an enhanced ability to retrieve and monitor short-term variations in plant physiological condition. Supplemental estimates of photosynthetic capacity or light-use-efficiency derived from hyperspectral reflectance (Hall et al., 2008; Serbin et al., 2012) and chlorophyll fluorescence observations (Joiner et al., 2014), have the potential to detect photosynthetic down-regulation immediately and diagnose vegetation stress before chlorophyll reductions take place. Although this information is not being distributed on a routine basis by the existing suite of space satellites, prospective launches of the proposed ESA candidate fluorescence explorer (FLEX) and the Hyperspectral Infrared Imager (HyspIRI) missions would enable complimentary use of important operational proxies (based on $\mathrm{Chl}_{1}$, hyperspectral and chlorophyll fluorescence approaches) within a multi-constraint framework, facilitating consistent and time-critical information on overall photosynthetic performance in space.

A final obstacle for successful integration and application of $\mathrm{Chl}_{1}$ information within TBMs depends on the validity of adopted model formulations and parameterizations. Currently, there is a lack of consensus in adopted values and parameterizations of $V_{\max }^{25}$ in TBMs (Rogers, 2014), as it tends to function more as a tunable model-dependent parameter to compensate for model-specific errors (Bonan et al., 2011). However, the use of $V_{\max }^{25}$ data constrained by space observations (e.g. $\mathrm{Chl}_{1}$ ) or from the growing database of plant traits (Kattge et al., 2011), necessitates consistent and physically-realistic formulations of leaf photosynthesis, which are well-constrained by data on kinetic constants and temperature dependencies from the experimental literature. In this study, an updated parameterization of the CLM leaf photosynthesis-conductance model was outlined based on a literature synthesis, and the application of the revised scheme was found to be essential for matching modeled and observed fluxes in maize and soybean when using $\mathrm{Chl}_{1}$ as an observational constraint on $V_{\text {max }}^{25}$. Significant uncertainty remains in the specification of optimal and spatially representative model parameters. Further studies are needed to arrive at a robust set of PFT-specific parameterizations to use in the TBMs, and the range of PFTs may 
need to be expanded in order to more accurately represent the dynamics of physiological responses between individual species.

\section{4. Conclusions}

Results from this study highlight the utility of $\mathrm{Ch}_{1}$ as an observational indicator of the magnitude and seasonal variability in $V_{\max }^{25}$, which can be used as a key input to TBMs for describing leaf photosynthetic capacity. A semi-mechanistic relationship between $V_{\max }^{25}$ and $\mathrm{Chl}_{1}$ was carefully parameterized based on an extensive literature synthesis and evaluated in fields of maize and soybean, with the provided parameterizations allowing for extension to other important agricultural crops. The applicability of the established $V_{\max }^{25}-\mathrm{Chl}_{1}$ regressions within the leaf photosynthesis schemes of TBMs relies in large part on adopted parameterizations of photosynthesis parameters and their temperature dependencies. A robust set of PFT-specific parameterizations that are well-constrained by data from the experimental literature will be key towards the effective use of $V_{\max }^{25}$ values constrained by observational data, as outlined in this study.

Considering the wide range of values of $V_{\max }^{25}$ used in TBMs, in addition to potentially large spatiotemporal variations in response to plant phenology and environmental stressors, there is a critical need for an observational constraint on $V_{\max }^{25}$. The convenience of $\mathrm{Ch}_{1}$ information in this context comes from the typically strong correlation with $\mathrm{N}$ and the ability to retrieve $\mathrm{Chl}_{1}$ directly from satellite-observed reflectances by inversion of canopy radiative transfer models (CRTMs). Challenges associated with $\mathrm{Chl}_{1}$ retrieval from space observations can be a limiting factor. Future work will need to focus on further development of image-based regularization techniques and the exploitation of multi-sensor data streams and enhanced spectral information within physically-realistic CRTMs, in an effort to better discriminate contributions from the atmosphere, leaf, canopy and soil and achieve higher estimation accuracies of leaf biochemical constituents (Houborg et al., 2015). The combination of $\mathrm{Chl}_{1}$ information with alternative proxies of photosynthetic efficiency (e.g. chlorophyll fluorescence observations), should also be an important objective for future research, as it has potential for producing more consistent and time-critical information needed to accurately inform models on the dynamics and variations in leaf photosynthetic capacity. The development of an observationally-driven scheme for constraining $V_{\max }^{25}$ in space and time is a necessary step towards reducing uncertainties in model predicted GPP across seasons, years and plant communities. 


\section{Acknowledgements}

The research undertaken here was funded by the King Abdullah University of Science and Technology (KAUST). We appreciate the data provided by the Center for Advanced Land Management Information Technologies (CALMIT) and the Carbon Sequestration Program, University of Nebraska-Lincoln. This work was supported in part by International Incoming Marie Curie fellowship to Anatoly Gitelson.

This work used eddy covariance data acquired by the FLUXNET community and in particular by the following networks: AmeriFlux (U.S. Department of Energy, Biological and Environmental Research, Terrestrial Carbon Program (DE- FG02- 04ER63917 and DE- FG02- 04ER63911)), AfriFlux, AsiaFlux, CarboAfrica, CarboEuropeIP, CarboItaly, CarboMont, ChinaFlux, Fluxnet- Canada (supported by CFCAS, NSERC, BIOCAP, Environment Canada, and NRCan), GreenGrass, KoFlux, LBA, NECC, OzFlux, TCOS- Siberia, USCCC. We acknowledge the financial support to the eddy covariance data harmonization provided by CarboEuropeIP, FAO, GTOS, TCO, iLEAPS, Max Planck Institute for Biogeochemistry, National Science Foundation, University of Tuscia, Université Laval and Environment Canada and US Department of Energy and the database development and technical support from Berkeley Water Center, Lawrence Berkeley National Laboratory, Microsoft Research eScience, Oak Ridge National Laboratory, University of California, Berkeley and the University of Virginia.

\section{Appendix A}

Table A1 lists parameterizations of the coupled photosynthesis-conductance model adopted in this study and in the study of Bonan et al. (2011). The slope and offset of the stomatal conductance model were adjusted to better approximate conditions of the studied plants (Ball, 1988). Leaf absorptance of photosynthetically active radiation (PAR) $\left(\alpha_{v i s}\right)$ is fixed at 0.84 for crops, but may be more accurately estimated as a function of $\mathrm{Chl}_{1}$. An exponential relationship between $\alpha_{v i s}$ and $\mathrm{Chl}_{1}$ was established (supplemental Fig. 1) based on model runs with the PROSPECT leaf optical properties model (Feret et al., 2008; Jacquemoud and Baret, 1990), assuming standard ranges for the leaf mesophyll structure (1.0 2.5) and dry matter content (20 - $\left.60 \mathrm{~g} \mathrm{~m}^{-2}\right)$ and no brown pigments, since only PAR absorbed by chlorophyll pigments is used for photosynthesis (Zhang et al., 2005). The corresponding relationship is given as

$\alpha_{v i s}=0.917-0.555 \cdot \exp ^{-0.0824 \cdot C h l_{l}}$

Eq. A1 
Table A1. List of model parameterizations for the coupled photosynthesis conductance model adopted in this study and those used in Bonan et al. (2011). Nomenclature is consistent with that used in Bonan et al. (2011). Model equations provided in Bonan et al. (2011) were used unless otherwise noted in the text and table footnotes. The leaf temperature $\left(T_{l}\right)$ dependencies of photosynthesis parameters were modelled using energies of activation $\left(\mathrm{E}_{\mathrm{a}}\right)$ according to $\exp \left(\left[E\left(T_{l}-298\right)\right] /\left[298 R_{g a s} T_{l}\right]\right)$ or $\mathrm{Q} 10$ according to $Q_{10}^{\left(T_{l}-298\right) / 10}$. The formulation of the temperature stress functions are provided in Bonan et al. (2011).

\begin{tabular}{|c|c|c|c|c|c|c|}
\hline \multirow[t]{2}{*}{ Quantity } & \multirow[t]{2}{*}{ ID } & \multirow[t]{2}{*}{ Units } & \multicolumn{2}{|c|}{$\mathrm{C}_{3}$ (soybean) } & \multicolumn{2}{|c|}{$\mathrm{C}_{4}$ (maize) } \\
\hline & & & This study & Bonan et al. & This study & Bonan et al. \\
\hline Ball \& Berry slope & $m$ & & $9.3^{\mathrm{a}}$ & $9^{\mathrm{b}}$ & $3.2^{\mathrm{a}}$ & $4^{b}$ \\
\hline Ball \& Berry offset & $b$ & $\mu \mathrm{mol} \mathrm{m} \mathrm{m}^{-2} \mathrm{~s}^{-1}$ & $8000^{\mathrm{a}}$ & $10000^{\mathrm{b}}$ & $60000^{\mathrm{a}}$ & $40000^{\mathrm{b}}$ \\
\hline Maximum rate of carboxylation & $V_{\max }^{25}$ & $\mu \mathrm{mol} \mathrm{m} \mathrm{s}^{-2}$ & \multicolumn{2}{|c|}{57 or $f(C h l)$} & \multicolumn{2}{|c|}{57 or $f(C h l)$} \\
\hline Potential rate of electron transport & $J_{\max }^{25}$ & $\mu \mathrm{mol} \mathrm{m} \mathrm{s}^{-2}$ & \multicolumn{2}{|c|}{$2.0 V_{\max }^{25}{ }^{\mathrm{c}}$} & $2.0 V_{\max }^{25}$ & - \\
\hline Initial slope of $\mathrm{CO} 2$ response curve & $k_{e}^{25}$ & $\mu \mathrm{mol} \mathrm{m} \mathrm{m}^{-2}$ & \multicolumn{2}{|r|}{ - } & $18000 V_{\text {max }}^{25 \mathrm{~d}}$ & $20000 V_{\max }^{25}$ \\
\hline Quantum yield of $\mathrm{CO} 2$ uptake & $\varepsilon^{\prime}$ & $\mathrm{mol}_{\mathrm{CO} 2} \mathrm{~mol}^{-1}$ & \multicolumn{2}{|c|}{ - } & & $0.05^{\mathrm{b}}$ \\
\hline Quantum yield of electron transport & $\varepsilon$ & $\mathrm{mol}_{\text {electrons }} \mathrm{mol}^{-1}$ & \multicolumn{2}{|c|}{$0.85^{\mathrm{e}}$} & $0.7^{\mathrm{f}}$ & - \\
\hline Leaf absorptance $(400-700 \mathrm{~nm})$ & $\propto$ & & $f(C h l)$ & 0.84 & $f(C h l)$ & 0.84 \\
\hline Triose phosphate utilization & $T P U^{25}$ & $\mu \mathrm{mol} \mathrm{m} \mathrm{s}^{-2}$ & \multicolumn{2}{|c|}{$0.06 J_{\max }^{25 \mathrm{~g}}$} & \multicolumn{2}{|c|}{ - } \\
\hline Leaf dark respiration & $R_{d}^{25}$ & $\mu \mathrm{mol} \mathrm{m} \mathrm{m}^{-2}$ & \multicolumn{2}{|c|}{$0.015 R_{d}^{25}$} & \multicolumn{2}{|c|}{$0.025 R_{d}^{25}$} \\
\hline Michaelis-Menten constant, $\mathrm{CO} 2$ & $K_{c}^{25}$ & $\mathrm{~Pa}$ & $40.4^{\mathrm{h}}$ & $41^{\mathrm{j}}$ & \multicolumn{2}{|c|}{-} \\
\hline Michaelis-Menten constant, O2 & $K_{o}^{25}$ & $\mathrm{~Pa}$ & $24800^{\mathrm{h}}$ & $28209^{j}$ & \multicolumn{2}{|c|}{-} \\
\hline $\mathrm{CO} 2$ compensation point & $\Gamma_{*}^{25}$ & $\mathrm{~Pa}$ & $3.69^{\mathrm{h}}$ & $4.3^{\mathrm{j}}$ & \multicolumn{2}{|c|}{-} \\
\hline Co-limitation parameter & $\Theta_{c j}$ & & \multicolumn{2}{|c|}{0.98} & \multicolumn{2}{|c|}{$0.85^{\mathrm{d}}$} \\
\hline Co-limitation parameter & $\Theta_{i e}$ & & \multicolumn{2}{|c|}{0.95} & \multicolumn{2}{|c|}{$0.95^{\mathrm{d}}$} \\
\hline Curvature factor & $\Theta_{P S I I}$ & & $f\left(T_{L}\right)^{\mathrm{i}}$ & 0.7 & $f\left(T_{L}\right)^{\mathrm{i}}$ & \\
\hline Energy of activation for $V_{\max }$ & $E_{a}$ & $\mathrm{KJ} \mathrm{mol}^{-1}$ & $69.5^{\mathrm{k}}$ & $65.33^{\mathrm{j}}$ & \multicolumn{2}{|c|}{$\mathrm{Q}_{10}=2^{\mathrm{b}}$} \\
\hline Energy of deactivation for $V_{\max }$ & $H_{d}$ & $\mathrm{KJ} \mathrm{mol}^{-1}$ & $200^{\mathrm{k}}$ & $149.25^{\mathrm{c}}$ & \multirow{2}{*}{\multicolumn{2}{|c|}{$\begin{array}{l}\text { Bonan et al. (2011) limitation } \\
\text { functions used }\end{array}$}} \\
\hline Entropy factor for $V_{\max }$ & $\Delta S$ & $\mathrm{~J} \mathrm{~mol}^{-1} \mathrm{~K}^{-1}$ & $629.9^{\mathrm{k}}$ & $485^{\mathrm{c}}$ & & \\
\hline Energy of activation for $J_{\max }$ & $E_{a}$ & $\mathrm{KJ} \mathrm{mol}^{-1}$ & - & $43.54^{\mathrm{i}}$ & $77.90^{1}$ & - \\
\hline Optimum temperature $\left(J_{\max }\right)$ & $T_{o}$ & ${ }^{\circ} \mathrm{C}$ & $38^{\mathrm{m}}$ & - & \multicolumn{2}{|c|}{ - } \\
\hline Breath of the peak $\left(J_{\max }\right)$ & $\Omega$ & ${ }^{\circ} \mathrm{C}$ & $16.5^{\mathrm{m}}$ & - & \multicolumn{2}{|c|}{ - } \\
\hline Energy of deactivation for $J_{\max }$ & $H_{d}$ & $\mathrm{KJ} \mathrm{mol}^{-1}$ & - & $152.04^{\mathrm{c}}$ & \multicolumn{2}{|l|}{$191.929^{1}$} \\
\hline Entropy factor for $J_{\max }$ & $\Delta S$ & $\mathrm{~J} \mathrm{~mol}^{-1} \mathrm{~K}^{-1}$ & - & $495^{\mathrm{c}}$ & \multicolumn{2}{|l|}{$627^{1}$} \\
\hline Energy of activation for $R_{d}$ & $E_{a}$ & $\mathrm{KJ} \mathrm{mol}^{-1}$ & $46.39^{j}$ & $46.39^{\mathrm{j}}$ & & \\
\hline Energy of deactivation for $R_{d}$ & $H_{d}$ & $\mathrm{KJ} \mathrm{mol}^{-1}$ & $200^{\mathrm{k}}$ & $150.65^{\mathrm{c}}$ & Bonan et al. & ) limitation \\
\hline Entropy factor for $R_{d}$ & $\Delta S$ & $\mathrm{KJ} \mathrm{mol}^{-1} \mathrm{~K}^{-1}$ & $629.9^{\mathrm{k}}$ & $490^{\mathrm{c}}$ & & \\
\hline Energy of activation for $K_{c}$ & $E_{a}$ & $\mathrm{KJ} \mathrm{mol}^{-1}$ & $59.4^{\mathrm{n}}$ & $79.43^{\mathrm{j}}$ & & \\
\hline Energy of activation for $K_{o}$ & $E_{a}$ & $\mathrm{KJ} \mathrm{mol}^{-1}$ & $36.0^{\mathrm{n}}$ & $36.38^{\mathrm{j}}$ & & \\
\hline Energy of activation for $\Gamma_{*}$ & $E_{a}$ & $\mathrm{KJ} \mathrm{mol}^{-1}$ & $23.4^{\mathrm{n}}$ & $37.83^{\mathrm{j}}$ & & \\
\hline Energy of activation for $T P U$ & $E_{a}$ & $\mathrm{KJ} \mathrm{mol}^{-1}$ & & $.1^{\circ}$ & & \\
\hline Energy of deactivation for $T P U$ & $H_{d}$ & $\mathrm{KJ} \mathrm{mol}^{-1}$ & $200^{\mathrm{k}}$ & $150.65^{\mathrm{c}}$ & & \\
\hline Entropy factor for $T P U$ & $\Delta S$ & $\mathrm{~J} \mathrm{~mol}^{-1} \mathrm{~K}^{-1}$ & $629.9^{\mathrm{k}}$ & $490^{\mathrm{c}}$ & & \\
\hline Energy of activation for $K_{e}$ & $E_{a}$ & $\mathrm{KJ} \mathrm{mol}^{-1}$ & & - & & \\
\hline
\end{tabular}

$723 \quad{ }^{\mathrm{a}}$ Ball 1988; ${ }^{\mathrm{b}}$ Sellers et al. (1996a, 1996b); ${ }^{\mathrm{c}}$ Leuning (2002); ${ }^{\mathrm{d}}$ Collatz et al. (1992); ${ }^{\mathrm{e}}$ Evans (1987) see Eq. A4. 
${ }^{\mathrm{f}}$ Oberhuber and Edwards (1993); ${ }^{\mathrm{g}}$ Wullschleger (1993); ${ }^{\mathrm{h}}$ von Caemmerer et al. (1994); ${ }^{\mathrm{j}}$ Bernacchi et al. (2001); ${ }^{\mathrm{i}}$ Bernacchi et al. (2003): $\Theta_{P S I I}=0.85 \exp \left(-0.5\left(\left(\left(T_{g}-25.8\right) / 14.84\right)^{2}+\left(\left(T_{l}-29.2\right) / 17.99\right)^{2}\right)\right)\left(\mathrm{T}_{\mathrm{g}}=25^{\circ} \mathrm{C}\right) ;{ }^{\mathrm{k}}$ Medlyn et al. (2002); ${ }^{1}$ Massad et al. (2007); ${ }^{\mathrm{m}}$ June et al. (2004) as reported in Bernacchi et al. (2013): $J_{\max }=J_{\max }^{25} \frac{\left(\left(25-T_{o}\right) / \Omega\right)^{2}}{\left(\left(T_{L}-T_{o}\right) / \Omega\right)^{2}} ;{ }^{\mathrm{n}}$ Farquhar et al. $(1980) ;{ }^{\circ}$ Harley et al. (1992).

For $\mathrm{C}_{3}$ plants, the main parameterization differences relate to adopted Rubisco kinetic parameters and temperature functions for photosynthetic parameters. Although the Michaelis-Menten constants of Rubisco for $\mathrm{CO}_{2}\left(K_{c}^{25}\right)$ and $\mathrm{O}_{2}\left(K_{o}^{25}\right)$ and the $\mathrm{CO}_{2}$ compensation point in the absence of day respiration are believed to be intrinsic properties of the Rubisco enzyme, reported values vary considerably (Bernacchi et al., 2001; von Caemmerer, 2000). Differences in measurement protocol (in-vitro assays versus in-vivo gas exchange measurements and assumptions regarding the mesophyll conductance) and plants studied, may explain the observed discrepancies (Bernacchi et al., 2002; Caemmerer et al., 1994; Walker and Cousins, 2013). The in-vivo estimate of $\Gamma_{*}^{25}$ (4.3) determined for tobacco leaves in Bernacchi et al. (2001) and adopted by Bonan et al. (2011) lies at the high end of reported values (Badger and Collatz, 1977; Medlyn et al., 2002). Tcherkez et al. (2006) reported an inverse correlation between Rubisco specificity $\left(S_{C / O}\right)$ and the catalytic Rubisco turnover rate $\left(K_{c a t}\right)$ and the relatively low value of $K_{c a t}^{25}$ reported for soybean (Table 2) may suggest that a lower value of $\Gamma_{*}^{25}$ should be used for applications over soybean in order to satisfy the direct inverse relationship between $S_{C / O}$ and $\Gamma_{*}\left(\Gamma_{*}=0.5 \cdot 0 / S_{c / o}\right)$. Accordingly, the lower estimate of $\Gamma_{*}^{25}$ (3.69) determined in-vivo using gas exchange data and with the assumption of an infinite mesophyll conductance (Caemmerer et al., 1994) is adopted here for soybean. We assume a more conservative temperature response of $\Gamma_{*}$ (Farquhar et al., 1980) in accordance with Jordan and Ogren (1984), Brooks and Farquhar (1985) and Bernacchi et al. (2002). For consistency, values of $K_{c}^{25}$ and $K_{o}^{25}$ are also adopted from von Caemmerer et al. (1994) and activation energies taken from Farquhar et al. (1980), which is consistent with data recorded for soybean plants (Laing et al., 1974).

The high temperature stress function used for $V_{\max }$ in Bonan et al. (2011) assumes an optimum temperature $\left(\mathrm{T}_{\mathrm{opt}}\right)$ of $33^{\circ} \mathrm{C}$. However results in Bernacchi et al. (2001) on tobacco plants, do not support the addition of a deactivation term at temperatures below $40^{\circ} \mathrm{C}$ and Houborg et al. (2009) also found temperature deactivation below $40^{\circ} \mathrm{C}$ inappropriate for soybean cultivars. In this study, $V_{\text {max }}$ is adjusted for different leaf temperatures using energies of activation and deactivation specific to soybean, with a $\mathrm{T}_{\mathrm{opt}}$ of $41.9^{\circ} \mathrm{C}$ as reported in Medlyn et al. (2002). The temperature response of the potential electron transport rate $\left(J_{\max }\right)$ is taken from Bernacchi et al. (2013) following June et al. (2004), who provide parameter values specific to soybean. 
757 Temperature response functions for $\mathrm{C}_{4}$ plants have been much less studied and we maintain the $\mathrm{C}_{4}$ 758 specific functions (Collatz et al., 1992; Sellers et al., 1996) that account for gradual deactivation at high 759 and low temperatures. Bonan et al. (2011) model the light-limited rate $\left(w_{j}\right)$ for $\mathrm{C}_{4}$ plants as a function of 760 the quantum yield of $\mathrm{CO}_{2}$ uptake $\left(\varepsilon^{\prime}\right)$ multipled by the absorbed photon flux $\left(\alpha_{v i s} \cdot I\right)$ with no maximum 761 limit. However, similar to $\mathrm{C}_{3}$ photosynthesis, it can also be approximated in terms of the electron 762 transport rate (Kim et al., 2007; Massad et al., 2007; von Caemmerer, 2000) as:

$764 \quad w_{j}=\frac{(1-x)}{3} J=\frac{J}{5}$

Eq. A2

$J=\left(I_{2}+J_{\max }-\sqrt{\left(I_{2}+J_{\max }\right)^{2}-4 \Theta_{P S I I} I_{2} J_{\max }}\right) /\left(2 \Theta_{P S I I}\right)$

Eq. A3

when assuming a value of 0.4 for the partitioning factor ( $\mathrm{x}$ ) of electron transport between $\mathrm{C}_{3}$ and $\mathrm{C}_{4}$ cycles. We model the dependence of $w_{j}$ on the electron transport rate $(\mathrm{J})$ using a non-rectangular hyperbolic function (e.g. Farquhar and Wong, 1984) that incorporates $J_{\max }$ and PAR absorbed by photosystem II $\left(\mathrm{I}_{2}\right)$ according to:

where $\Theta_{P S I I}$ represents a curvature factor and $\mathrm{I}_{2}$ may be expressed in terms of the maximum quantum yield of electron transport $(\varepsilon)$ (Bernacchi et al., 2003) as:

$I_{2}=I \cdot \alpha_{v i s} \cdot \varepsilon \cdot 0.5$

Eq. A4

Here, I is the incident radiation and the multiplication with 0.5 is because photosystem II absorbs half the available energy (von Caemmerer, 2000). $\varepsilon$ is commonly expressed as $1-f$ (e.g. von Caemmerer, 2000; De Pury and Farquhar, 1997), where $f$ is a spectral correction factor typically assigned a value of 0.15 for $\mathrm{C}_{3}$ plants (Evans, 1987) and the resulting value of $\varepsilon(0.85)$ adopted here (Table A1) is consistent with other studies on $\mathrm{C}_{3}$ plants (Bernacchi et al., 2003; Long et al., 1993; Oberhuber and Edwards, 1993). $\varepsilon$ tends to be lower for $\mathrm{C}_{4}$ plants and we adopt a value of 0.75 as recorded for maize (Krall and Edwards, 1990; Oberhuber and Edwards, 1993). The curvature factor $\left(\Theta_{P S I I}\right)$ is most often assigned a fixed value of 0.7 (Evans, 1989) but is prescribed here as a function of leaf and growth temperature $\left(=25^{\circ} \mathrm{C}\right)$ according to Bernacchi et al. (2003) (Table A1).

In $\mathrm{C}_{3}$ species, $V_{\max }$ and $J_{\max }$ have been shown to be tightly coupled with reported $J_{\max }^{25} / V_{\max }^{25}$ ratios on the order of 2 (Kattge et al., 2007; Leuning, 2002; Wohlfahrt et al., 1999). The relationship between these 
two component processes has not been investigated for $\mathrm{C}_{4}$ species and therefore assumes the same ratio for $\mathrm{C}_{4}$ species. The coupling of $J_{\max }^{25}$ with $V_{\max }^{25}$ serves as a convenient mechanism for facilitating $\mathrm{Chl}_{1}$ constraint on the light-limited rate (Houborg et al., 2013). The temperature dependence of $J_{\max }$ typically differs from that of $V_{\max }$ (Leuning, 2002), although investigations with $\mathrm{C}_{4}$ plants are limited. Here we assume energies of activation and deactivation derived by Massad et al. (2007) based on leaf gas exchange measurements on maize plants. The effect of the updated parameterization scheme on the simulation of GPP, and the sensitivity of the model to changes in $V_{\max }^{25}$ are evaluated in Section 3.2.

\section{References}

Agarwal, D.A., Humphrey, M., Beekwilder, N.F., Jackson, K.R., Goode, M.M., van Ingen, C., 2010. A data-centered collaboration portal to support global carbon-flux analysis. Concurr. Comput. Pract. Exp. 22, 2323-2334. doi:10.1002/cpe.1600

Badger, M.R., Collatz, G.J., 1977. Studies on the kinetic mecha- nism of ribulose-1,5-bisphosphate carboxylase and oxygenase reactions with particular reference to the effect of temperature on kinetic parameters. Carnegie Inst. Washingt. Yearb. 76, 355-361.

Baldocchi, D., Finnigan, J., Wilson, K., Paw U, K.T., Falge, E., 2000. On measuring net ecosystem carbon exchange over tall vegetation on complex terrain, in: Boundary-Layer Meteorology. pp. 257291.

Ball, J.T., 1988. An analysis of stomatal conductance. Stanford University.

Ball, J.T., Woodrow, I.E., Berry, J.A., 1987. A model predicting stomatal conductance and its contribution to the control of photosynthesis under different environmental conditions, in: Biggins, J. (Ed.), Progress in Photosynthesis Research. Nijhoff, Dodrecht, pp. 221-225.

Baret, F., 1991. Vegetation canopy reflectance: Factors of variation and application for agriculture, in: Hunt, D. (Ed.), Physical Measurements and Signatures in Remote Sensing. Courchevel, France, pp. $145-167$.

Bauerle, W.L., Oren, R., Way, D. a, Qian, S.S., Stoy, P.C., Thornton, P.E., Bowden, J.D., Hoffman, F.M., Reynolds, R.F., 2012. Photoperiodic regulation of the seasonal pattern of photosynthetic capacity and the implications for carbon cycling. Proc. Natl. Acad. Sci. U. S. A. 109, 8612-7. doi:10.1073/pnas.1119131109

Bernacchi, C.J., Bagley, J.E., Serbin, S.P., Ruiz-Vera, U.M., Rosenthal, D.M., Vanloocke, A., 2013. Modelling $\mathrm{C}_{3}$ photosynthesis from the chloroplast to the ecosystem. Plant. Cell Environ. 36, 164157. doi:10.1111/pce.12118

Bernacchi, C.J., Pimentel, C., Long, S.P., 2003. In vivo temperature response functions of parameters required to model RuBP-limited photosynthesis 1419-1430. 
Bernacchi, C.J., Portis, A.R., Nakano, H., Caemmerer, S. Von, Long, S.P., 2002. Temperature Response of Mesophyll Conductance. Implications for the Determination of Rubisco Enzyme Kinetics and for Limitations to Photosynthesis in Vivo 130, 1992-1998. doi:10.1104/pp.008250.water

Bernacchi, C.J., Singsaas, E.L., Pimentel, C., Jr, A.R.P., Long, S.P., 2001. Improved temperature response functions for models of Rubisco-limited photosynthesis 253-259.

Bonan, G.B., Lawrence, P.J., Oleson, K.W., Levis, S., Jung, M., Reichstein, M., Lawrence, D.M., Swenson, S.C., 2011. Improving canopy processes in the Community Land Model version 4 (CLM4) using global flux fields empirically inferred from FLUXNET data. J. Geophys. Res. 116, 1-22. doi:10.1029/2010JG001593

Brooks, A., Farquhar, G.D., 1985. Effect of temperature on the CO2/O 2 specificity of ribulose-1,5bisphosphate carboxylase/oxygenase and the rate of respiration in the light $\square$ : Estimates from gas exchange measurements on spinach. Planta 165, 397-406. doi:10.1007/BF00392238

Caemmerer, S., Evans, J.R., Hudson, G.S., Andrews, T.J., 1994. Planta in vivo inferred from measurements of photosynthesis in leaves of transgenic tobacco 88-97.

Chen, H., Dickinson, R.E., Dai, Y., Zhou, L., 2011. Sensitivity of simulated terrestrial carbon assimilation and canopy transpiration to different stomatal conductance and carbon assimilation schemes. Clim. Dyn. 36, 1037-1054. doi:10.1007/s00382-010-0741-2

Ciganda, V., Gitelson, A., Schepers, J., 2009. Non-destructive determination of maize leaf and canopy chlorophyll content. J. Plant Physiol. 166, 157-67. doi:10.1016/j.jplph.2008.03.004

Clark, D.B., Mercado, L.M., Sitch, S., Jones, C.D., Gedney, N., Best, M.J., Pryor, M., Rooney, G.G., Essery, R.L.H., Blyth, E., Boucher, O., Harding, R.J., Huntingford, C., Cox, P.M., 2011. The Joint UK Land Environment Simulator (JULES), model description - Part 2: Carbon fluxes and vegetation dynamics. Geosci. Model Dev. 4, 701-722. doi:10.5194/gmd-4-701-2011

Clevers, J.G.P.W., Gitelson, A.A., 2013. Remote estimation of crop and grass chlorophyll and nitrogen content using red-edge bands on Sentinel-2 and -3. Int. J. Appl. Earth Obs. Geoinf. 23, 344-351. doi:10.1016/j.jag.2012.10.008

Collatz, G., Ribas-Carbo, M., Berry, J., 1992. Coupled photosynthesis-stomatal conductance model for leaves of C4 plants. Aust. J. Plant Physiol. 19, 519-538.

Collatz, G.., Ball, J.T., Grivet, C., Berry, J., 1991. Physiological and environmental regulation of stomatal conductance, photosynthesis and transpiration: a model that includes a laminar boundary layer. Agric. For. Meteorol. 54, 107-136.

Combal, B., Baret, F., Weiss, M., Trubuil, A., 2002. Retrieval of canopy biophysical variables from bidirectional reflectance: Using prior information to solve the ill-posed inverse problem. Remote Sens. Environ. 84, 1-15.

Croft, H., Chen, J.M., Zhang, Y., 2014. Temporal disparity in leaf chlorophyll content and leaf area index across a growing season in a temperate deciduous forest. Int. J. Appl. Earth Obs. Geoinf. 33, 312320. doi:10.1016/j.jag.2014.06.005 
Dash, J., Curran, P.J., 2007. Evaluation of the MERIS terrestrial chlorophyll index (MTCI). Adv. Sp. Res. 39, 100-104. doi:10.1016/j.asr.2006.02.034

De Pury, D.G.G., Farquhar, G.D., 1997. Simple scaling of photosynthesis from leaves to canopies without the errors of big-leaf models. Plant, Cell Environ. 20, 537-557. doi:10.1111/j.13653040.1997.00094.x

Desai, A.R., Richardson, A.D., Moffat, A.M., Kattge, J., Hollinger, D.Y., Barr, A., Falge, E., Noormets, A., Papale, D., Reichstein, M., Stauch, V.J., 2008. Cross-site evaluation of eddy covariance GPP and RE decomposition techniques. Agric. For. Meteorol. 148, 821-838. doi:10.1016/j.agrformet.2007.11.012

Evans, J., 1989. Photosynthesis and nitrogen relationships in leaves of C3 plants. Oecologia 78, 9-19.

Evans, J.R., 1987. The Dependence of Quantum Yield on Wavelength and Growth Irradiance. Aust. J. Plant Physiol 14, 69-79.

Farquhar, G., Caemmerer, S., Berry, J., 1980. A Biochemical Model of Photosynthetic CO2 Assimilation in Leaves of C3 Species. Planta 90, 78-90.

Farquhar, G.D., Wong, S.C., 1984. An Empirical Model of Stomatal Conductance. Aust. J. Plant Physiol. $11,191-210$.

Feret, J.-B., François, C., Asner, G.P., Gitelson, A.A., Martin, R.E., Bidel, L.P.R., Ustin, S.L., le Maire, G., Jacquemoud, S., 2008. PROSPECT-4 and 5: Advances in the leaf optical properties model separating photosynthetic pigments. Remote Sens. Environ. 112, 3030-3043. doi:10.1016/j.rse.2008.02.012

Gao, F., Masek, J., Schwaller, M., Hall, F., 2006. On the blending of the Landsat and MODIS surface reflectance: predicting daily Landsat surface reflectance. IEEE Trans. Geosci. Remote Sens. 44, 2207-2218. doi:10.1109/TGRS.2006.872081

Ghannoum, O., Evans, J.R., Chow, W.S., Andrews, T.J., Conroy, J.P., Caemmerer, S. Von, 2005. Faster Rubisco Is the Key to Superior Nitrogen-Use Efficiency in NADP-Malic Enzyme Relative to NADMalic Enzyme C4 Grasses. Plant Physiol. 137, 638-650. doi:10.1104/pp.104.054759.638

Gitelson, A.A., Keydan, G.P., Merzlyak, M.N., 2006a. Three-band model for noninvasive estimation of chlorophyll, carotenoids, and anthocyanin contents in higher plant leaves. Geophys. Res. Lett. 33, L11402. doi:10.1029/2006GL026457

Gitelson, A.A., Peng, Y., Arkebauer, T.J., Schepers, J., 2014. Relationships between gross primary production, green LAI, and canopy chlorophyll content in maize: Implications for remote sensing of primary production. Remote Sens. Environ. 144, 65-72. doi:10.1016/j.rse.2014.01.004

Gitelson, A.A., Vina, A., Arkebauer, T.J., Rundquist, D.C., Keydan, G., Leavitt, B., 2003. Remote estimation of leaf area index and green leaf biomass in maize canopies. Geophys. Res. Lett. 30, 1248. doi:10.1029/2002GL016450 
Gitelson, A.A., Vina, A., Ciganda, V., Rundquist, D.C., Arkebauer, T.J., 2005. Remote estimation of canopy chlorophyll content in crops. Geophys. Res. Lett. 32, L08403. doi:10.1029/2005GL022688

Gitelson, A.A., Viña, A., Verma, S.B., Rundquist, D.C., Arkebauer, T.J., Keydan, G., Leavitt, B., Ciganda, V., Burba, G.G., Suyker, A.E., 2006b. Relationship between gross primary production and chlorophyll content in crops: Implications for the synoptic monitoring of vegetation productivity. J. Geophys. Res. 111, D08S11. doi:10.1029/2005JD006017

Groenendijk, M., Dolman, a. J., van der Molen, M.K., Leuning, R., Arneth, a., Delpierre, N., Gash, J.H.C., Lindroth, a., Richardson, a. D., Verbeeck, H., Wohlfahrt, G., 2011. Assessing parameter variability in a photosynthesis model within and between plant functional types using global Fluxnet eddy covariance data. Agric. For. Meteorol. 151, 22-38. doi:10.1016/j.agrformet.2010.08.013

Guindin-Garcia, N., Gitelson, A.A., Arkebauer, T.J., Shanahan, J., Weiss, A., 2012. An evaluation of MODIS 8- and 16-day composite products for monitoring maize green leaf area index. Agric. For. Meteorol. 161, 15-25. doi:10.1016/j.agrformet.2012.03.012

Hall, F.G., Hilker, T., Coops, N.C., Lyapustin, A., Huemmrich, K.F., Middleton, E., Margolis, H., Drolet, G., Black, T.A., 2008. Multi-angle remote sensing of forest light use efficiency by observing PRI variation with canopy shadow fraction. Remote Sens. Environ. 112, 3201-3211. doi:10.1016/j.rse.2008.03.015

Hollinger, D.Y., Richardson, A.D., 2005. Uncertainty in eddy covariance measurements and its application to physiological models, in: Tree Physiology. pp. 873-885.

Homolová, L., Malenovský, Z., Clevers, J.G.P.W., García-Santos, G., Schaepman, M.E., 2013. Review of optical-based remote sensing for plant trait mapping. Ecol. Complex. 15, 1-16. doi:10.1016/j.ecocom.2013.06.003

Houborg, R., Anderson, M.C., Norman, J.M., Wilson, T., Meyers, T., 2009. Intercomparison of a "bottom-up" and "top-down" modeling paradigm for estimating carbon and energy fluxes over a variety of vegetative regimes across the U.S. Agric. For. Meteorol. 149, 2162-2182. doi:10.1016/j.agrformet.2009.10.002

Houborg, R., Cescatti, A., Migliavacca, M., Kustas, W.P., 2013. Agricultural and Forest Meteorology Satellite retrievals of leaf chlorophyll and photosynthetic capacity for improved modeling of GPP $\backsim$. Agric. For. Meteorol. 177, 10-23. doi:10.1016/j.agrformet.2013.04.006

Houborg, R., McCabe, M., Cescatti, A., Gao, F., Schull, M., Gitelson, A., 2015. Joint leaf chlorophyll content and leaf area index retrieval from Landsat data using a regularized model inversion system (REGFLEC). Remote Sens. Environ. 159, 203-221. doi:10.1016/j.rse.2014.12.008

Jacquemoud, S., Baret, F., 1990. PROSPECT: A model of leaf optical properties spectra. Remote Sens. Environ. 34, 75-91. doi:10.1016/0034-4257(90)90100-Z

Jacquemoud, S., Verhoef, W., Baret, F., Bacour, C., Zarco-Tejada, P.J., Asner, G.P., François, C., Ustin, S.L., 2009. PROSPECT+SAIL models: A review of use for vegetation characterization. Remote Sens. Environ. 113, S56-S66. doi:10.1016/j.rse.2008.01.026 
Joiner, J., Yoshida, Y., Vasilkov, A.P., Schaefer, K., Jung, M., Guanter, L., Zhang, Y., Garrity, S., Middleton, E.M., Huemmrich, K.F., Gu, L., Belelli Marchesini, L., 2014. The seasonal cycle of satellite chlorophyll fluorescence observations and its relationship to vegetation phenology and ecosystem atmosphere carbon exchange. Remote Sens. Environ. 152, 375-391. doi:10.1016/j.rse.2014.06.022

Jordan, D.B., Ogren, W.L., 1984. The CO2/O2 specificity of ribulose 1,5-bisphosphate carboxylase/oxygenase. Planta 161, 308-313.

June, T., Evans, J.R., Farquhar, D., 2004. A simple new equation for the reversible temperature dependence of photosynthetic electron transport $\square$ : a study on soybean leaf. Funct. Plant Ecol. 275283.

Kalfas, J.L., Xiao, X., Vanegas, D.X., Verma, S.B., Suyker, A.E., 2011. Modeling gross primary production of irrigated and rain-fed maize using MODIS imagery and CO2 flux tower data. Agric. For. Meteorol. 151, 1514-1528. doi:10.1016/j.agrformet.2011.06.007

Kattge, J., Díaz, S., Lavorel, S., Prentice, I.C., Leadley, P., Bönisch, G., Garnier, E., Westoby, M., Reich, P.B., Wright, I.J., Cornelissen, J.H.C., Violle, C., Harrison, S.P., Van BODEGOM, P.M., Reichstein, M., Enquist, B.J., Soudzilovskaia, N. a., Ackerly, D.D., Anand, M., Atkin, O., Bahn, M., Baker, T.R., Baldocchi, D., Bekker, R., Blanco, C.C., Blonder, B., Bond, W.J., Bradstock, R., Bunker, D.E., Casanoves, F., Cavender-Bares, J., Chambers, J.Q., Chapin Iii, F.S., Chave, J., Coomes, D., Cornwell, W.K., Craine, J.M., Dobrin, B.H., Duarte, L., Durka, W., Elser, J., Esser, G., Estiarte, M., Fagan, W.F., Fang, J., Fernández-Méndez, F., Fidelis, a., Finegan, B., Flores, O., Ford, H., Frank, D., Freschet, G.T., Fyllas, N.M., Gallagher, R. V., Green, W. a., Gutierrez, a. G., Hickler, T., Higgins, S.I., Hodgson, J.G., Jalili, a., Jansen, S., Joly, C. a., Kerkhoff, a. J., Kirkup, D., Kitajima, K., Kleyer, M., Klotz, S., Knops, J.M.H., Kramer, K., Kühn, I., Kurokawa, H., Laughlin, D., Lee, T.D., Leishman, M., Lens, F., Lenz, T., Lewis, S.L., Lloyd, J., Llusià, J., Louault, F., Ma, S., Mahecha, M.D., Manning, P., Massad, T., Medlyn, B.E., Messier, J., Moles, a. T., Müller, S.C., Nadrowski, K., Naeem, S., Niinemets, Ü., Nöllert, S., Nüske, a., Ogaya, R., Oleksyn, J., Onipchenko, V.G., Onoda, Y., Ordoñez, J., Overbeck, G., Ozinga, W. a., Patiño, S., Paula, S., Pausas, J.G., Peñuelas, J., Phillips, O.L., Pillar, V., Poorter, H., Poorter, L., Poschlod, P., Prinzing, a., Proulx, R., Rammig, a., Reinsch, S., Reu, B., Sack, L., Salgado-Negret, B., Sardans, J., Shiodera, S., Shipley, B., Siefert, a., Sosinski, E., Soussana, J.-F., Swaine, E., Swenson, N., Thompson, K., Thornton, P., Waldram, M., Weiher, E., White, M., White, S., Wright, S.J., Yguel, B., Zaehle, S., Zanne, a. E., Wirth, C., 2011. TRY - a global database of plant traits. Glob. Chang. Biol. 17, 29052935. doi:10.1111/j.1365-2486.2011.02451.x

Kattge, J., Knorr, W., Farquhar, T., 2007. Temperature acclimation in a biochemical model of photosynthesis $\square$ : a reanalysis of data from 36 species. Plant. Cell Environ. 30, 1176-1190. doi:10.1111/j.1365-3040.2007.01690.x

Kattge, J., Knorr, W., Raddatz, T., Wirth, C., 2009. Quantifying photosynthetic capacity and its relationship to leaf nitrogen content for global-scale terrestrial biosphere models. Glob. Chang. Biol. 15, 976-991. doi:10.1111/j.1365-2486.2008.01744.x

Keenan, T.F., Baker, I., Barr, A., Ciais, P., Davis, K., Dietze, M., Dragoni, D., Gough, C.M., Grant, R., Hollinger, D., Hufkens, K., Poulter, B., McCaughey, H., Raczka, B., Ryu, Y., Schaefer, K., Tian, H., Verbeeck, H., Zhao, M., Richardson, A.D., 2012. Terrestrial biosphere model performance for inter- 
annual variability of land-atmosphere CO2 exchange. Glob. Chang. Biol. 18, 1971-1987. doi:10.1111/j.1365-2486.2012.02678.x

Kim, S., Gitz, D., Sicher, R., Baker, J., Timlin, D., Reddy, V., 2007. Temperature dependence of growth, development, and photosynthesis in maize under elevated CO2. Environ. Exp. Bot. 61, 224-236. doi:10.1016/j.envexpbot.2007.06.005

Knorr, W., 2000. Annual and interannual CO2 exchanges of the terrestrial biosphere: process-based simulations and uncertainties. Glob. Ecol. Biogeogr. 9, 225-252. doi:10.1046/j.13652699.2000.00159.x

Knorr, W., Heimann, M., 2001. Uncertainties in global terrestrial biosphere modeling: 1. A comprehensive sensitivity analysis with a new photosynthesis and energy balance scheme. Global Biogeochem. Cycles 15, 207-225. doi:10.1029/1998GB001059

Krall, J.P., Edwards, G.E., 1990. Quantum Yields of Photosystem II Electron Transport and Carbon Dioxide Fixation in C4 Plants. Aust. J. Plant Physiol.17 17, 579-88.

Lawrence, D.M., Oleson, K.W., Flanner, M.G., Thornton, P.E., Swenson, S.C., Lawrence, P.J., Zeng, X., Yang, Z.-L., Levis, S., Sakaguchi, K., Bonan, G.B., Slater, A.G., 2011. Parameterization improvements and functional and structural advances in Version 4 of the Community Land Model. J. Adv. Model. Earth Syst. 3, 1-27. doi:10.1029/2011MS000045

Legates, D.R., McCabe, G.J., 1999. Evaluating the use of "goodness-of-fit" Measures in hydrologic and hydroclimatic model validation. Water Resour. Res. 35, 233-241. doi:10.1029/1998WR900018

Leuning, R., 2002. Temperature dependence of two parameters in a photosynthesis model. Plant. Cell Environ. 25, 1205-1210.

Li, F., Kustas, W.P., Anderson, M.C., Prueger, J.H., Scott, R.L., 2008. Effect of remote sensing spatial resolution on interpreting tower-based flux observations. Remote Sens. Environ. 112, 337-349. doi:10.1016/j.rse.2006.11.032

Long, S.P., Postl, W.F., Bolh - r-Nordenkampf, H.R., 1993. Quantum yields for uptake of carbon dioxide in C3 vascular plants of contrasting habitats and taxonomic groupings. Planta 189, 226-234. doi:10.1007/BF00195081

Maekawa, T., Kokubun, M., 2005. Correlation of Leaf Nitrogen, Chlorophyll and Rubisco Contents with Photosynthesis in a Supernodulating Soybean Genotype Sakukei 4. Plant Prod. Sci. 8, 419-426. doi:10.1626/pps.8.419

Massad, R.-S., Tuzet, A., Bethenod, O., 2007. The effect of temperature on C(4)-type leaf photosynthesis parameters. Plant. Cell Environ. 30, 1191-204. doi:10.1111/j.1365-3040.2007.01691.x

Medlyn, B.E., Dreyer, E., Ellsworth, D., Forstreuter, M., Harley, P.C., Kirschbaum, M.U.F., Roux, X.L.E., 2002. Temperature response of parameters of a biochemically based model of photosynthesis. II. A review of experimental data. Plant, Cell Environ. 25, 1167-1179. 
Moncrieff, J.B., Malhi, Y., Leuning, R., 1996. The propagation of errors in long-term measurements of land-atmosphere fluxes of carbon and water. Glob. Chang. Biol. 2, 231-240.

Monteith, J.L., 1972. Climate and the efficiency of crop production. J. Appl. Ecol. 9, 747-766.

O’Neill, E.J., Batey, T., Cresser, M.S., 1984. Effect of nitrogen supply on barley pigment concentrations. Plant Soil 77, 315-326. doi:10.1007/BF02182934

Oberhuber, W., Edwards, G.E., 1993. Temperature Dependence of the Linkage of Quantum Yield of Photosystem II to CO2 Fixation in C4 and C3 Plants. Plant Physiol. 101, 507-512.

Oleson, K.W., Lawrence, D.M., Gordon, B., Flanner, M.G., Kluzek, E., Peter, J., Levis, S., Swenson, S.C., Thornton, E., Dai, A., Decker, M., Dickinson, R., Feddema, J., Heald, C.L., Lamarque, J., Niu, G., Qian, T., Running, S., Sakaguchi, K., Slater, A., Stöckli, R., Wang, A., Yang, L., Zeng, X., Zeng, X., 2010. Technical Description of version 4.0 of the Community Land Model (CLM), NCAR Technical note. Boulder, Colorado.

Oleson, K.W., Niu, G.-Y., Yang, Z.-L., Lawrence, D.M., Thornton, P.E., Lawrence, P.J., Stöckli, R., Dickinson, R.E., Bonan, G.B., Levis, S., Dai, A., Qian, T., 2008. Improvements to the Community Land Model and their impact on the hydrological cycle. J. Geophys. Res. 113, 1-26. doi:10.1029/2007JG000563

Osaki, M., Iyoda, M., Tadano, T., 1995. Effect of nitrogen application and sink manipulation on the contents of Ribulose-1,5-Bisphosphate Carboxylase/Oxygenase, Phosphoenolpyruvate Carboxylase, and Chlorophyll in leaves of maize during the maturation stage. Soil Sci. Plant Nutr. 41, 295-303.

Post, H., Hendricks Franssen, H.J., Graf, A., Schmidt, M., Vereecken, H., 2015. Uncertainty analysis of eddy covariance $\mathrm{CO}_{2}$ flux measurements for different EC tower distances using an extended twotower approach. Biogeosciences 12, 1205-1221. doi:10.5194/bg-12-1205-2015

Reichstein, M., Falge, E., Baldocchi, D., Papale, D., Aubinet, M., Berbigier, P., Bernhofer, C., Buchmann, N., Gilmanov, T., Granier, A., Grunwald, T., Havrankova, K., Ilvesniemi, H., Janous, D., Knohl, A., Laurila, T., Lohila, A., Loustau, D., Matteucci, G., Meyers, T., Miglietta, F., Ourcival, J.-M., Pumpanen, J., Rambal, S., Rotenberg, E., Sanz, M., Tenhunen, J., Seufert, G., Vaccari, F., Vesala, T., Yakir, D., Valentini, R., 2005. On the separation of net ecosystem exchange into assimilation and ecosystem respiration: review and improved algorithm. Glob. Chang. Biol. 11, 1424-1439. doi:10.1111/j.1365-2486.2005.001002.x

Rogers, A., 2014. The use and misuse of V(c,max) in Earth System Models. Photosynth. Res. 119, 15-29. doi:10.1007/s11120-013-9818-1

Running, S.W., Nemani, R.R., Heinsch, F.A., Zhao, M., Reeves, M., Hashimoto, H., 2004. A continuous satellite-derived measure of global terrestrial primary production. Bioscience.

Sage, R.F., Pearcy, R.W., Seeman, J.R., 1987. The Nitrogen Use Efficiency of C3 and C4 Plants. Plant Physiol. 85, 355-359. 

Remote estimation, A., Schepers, J., Ferguson, R., Peng, Y., Shanahan, J., Rundquist, D., 2013. Appl. Earth Obs. Geoinf. 25, 47-54. doi:10.1016/j.jag.2013.04.003

Schull, M.A., Anderson, M.C., Houborg, R., Gitelson, A., Kustas, W.P., 2015. Thermal-based modeling of coupled carbon, water, and energy fluxes using nominal light use efficiencies constrained by leaf. Biogeosciences 12, 1511-1523. doi:10.5194/bg-12-1511-2015

Seemann, J.R., Sharkey, T.D., Wang, J., Osmond, C.B., 1987. Environmental effects on photosynthesis, nitrogen-use efficiency, and metabolite pools in leaves of sun and shade plants. Plant Physiol. 84, 796-802.

Sellers, P., Randall, D., Collatz, G., Berry, J., Field, C., Dazlich, D., Zhang, C., Collelo, G., Bounoua, L., 1996. A revised land surface parameterization (SiB2) for atmospheric GCMs. Part I: Model Formulation. J. ... 9, 676-705.

Serbin, S.P., Dillaway, D.N., Kruger, E.L., Townsend, P. a, 2012. Leaf optical properties reflect variation in photosynthetic metabolism and its sensitivity to temperature. J. Exp. Bot. 63, 489-502. doi:10.1093/jxb/err294

Sudo, E., Makino, A., Mae, T., 2003. Differences between rice and wheat in ribulose-1,5-bisphosphate regeneration capacity per unit of leaf-N content. Plant, Cell Environ. 26, 255-263. doi:10.1046/j.1365-3040.2003.00955.x

Suyker, A.E., Verma, S.B., 2010. Coupling of carbon dioxide and water vapor exchanges of irrigated and rainfed maize-soybean cropping systems and water productivity. Agric. For. Meteorol. 150, 553563. doi:10.1016/j.agrformet.2010.01.020

Tcherkez, G.G.B., Farquhar, G.D., Andrews, T.J., 2006. Despite slow catalysis and confused substrate specificity, all ribulose bisphosphate carboxylases may be nearly perfectly optimized. PNAS 103, 7246-51. doi:10.1073/pnas.0600605103

Theobald, J.C., Mitchell, R.A.C., Parry, M.A.J., Lawlor, D.W., 1998. Estimating the excess investment in ribulose-1, 5-bisphosphate carboxylase/oxygenase in leaves of spring wheat grown under elevated CO2. Plant Physiol. 118, 945-955.

Thornton, P.E., Zimmermann, N.E., 2007. An Improved Canopy Integration Scheme for a Land Surface Model with Prognostic Canopy Structure. J. Clim. 20, 3902-3923. doi:10.1175/JCLI4222.1

Verheijen, L.M., Brovkin, V., Aerts, R., Bönisch, G., Cornelissen, J.H.C., Kattge, J., Reich, P.B., Wright, I.J., van Bodegom, P.M., 2013. Impacts of trait variation through observed trait-climate relationships on performance of an Earth system model: a conceptual analysis. Biogeosciences 10, 5497-5515. doi:10.5194/bg-10-5497-2013

Verhoef, W., 1984. Light scattering by leaf layers with application to canopy reflectance modeling: The SAIL model. Remote Sens. Environ. 16, 125-141.

Verma, S.B., Dobermann, A., Cassman, K.G., Walters, D.T., Knops, J.M., Arkebauer, T.J., Suyker, A.E., Burba, G.G., Amos, B., Yang, H., Ginting, D., Hubbard, K.G., Gitelson, A. a., Walter-Shea, E. a., 
2005. Annual carbon dioxide exchange in irrigated and rainfed maize-based agroecosystems. Agric. For. Meteorol. 131, 77-96. doi:10.1016/j.agrformet.2005.05.003

Vermote, E.F., Tanre, D., Deuze, J.L., Herman, M., Morcette, J.-J., 1997. Second Simulation of the Satellite Signal in the Solar Spectrum, 6S: an overview. IEEE Trans. Geosci. Remote Sens. 35, 675686. doi:10.1109/36.581987

Von Caemmerer, S., 2000. Biochemical Models of Leaf Photosynthesis. CSIRO Publishing.

Walker, A.P., Beckerman, A.P., Gu, L., Kattge, J., Cernusak, L.A., Domingues, T.F., Scales, J.C., Wohlfahrt, G., Wullschleger, S.D., Woodward, F.I., 2014. The relationship of leaf photosynthetic traits - V cmax and $\mathrm{J}$ max - to leaf nitrogen, leaf phosphorus, and specific leaf area: a meta-analysis and modeling study. Ecol. Evol. 4, n/a-n/a. doi:10.1002/ece3.1173

Walker, B.J., Cousins, A.B., 2013. Influence of temperature on measurements of the CO2 compensation point: differences between the Laisk and O2-exchange methods. J. Exp. Bot. 64, 1893-905. doi:10.1093/jxb/ert058

Wohlfahrt, G., Bahn, M., Haubner, E., Horak, I., Michaeler, W., Rottmar, K., Tappeiner, U., Cernusca, a., 1999. Inter-specific variation of the biochemical limitation to photosynthesis and related leaf traits of 30 species from mountain grassland ecosystems under different land use. Plant, Cell Environ. 22, 1281-1296. doi:10.1046/j.1365-3040.1999.00479.x

Xu, L., Baldocchi, D.D., 2003. Seasonal trends in photosynthetic parameters and stomatal conductance of blue oak (Quercus douglasii) under prolonged summer drought and high temperature. Tree Physiol. $23,865-77$.

Yamori, W., Nagai, T., Makino, A., 2011. The rate-limiting step for $\mathrm{CO}(2)$ assimilation at different temperatures is influenced by the leaf nitrogen content in several C(3) crop species. Plant. Cell Environ. 34, 764-77. doi:10.1111/j.1365-3040.2011.02280.x

Zaehle, S., 2005. Effects of parameter uncertainties on the modeling of terrestrial biosphere dynamics. Global Biogeochem. Cycles 19. doi:10.1029/2004GB002395

Zaehle, S., Friend, a. D., 2010. Carbon and nitrogen cycle dynamics in the O-CN land surface model: 1. Model description, site-scale evaluation, and sensitivity to parameter estimates. Global Biogeochem. Cycles 24, 1-13. doi:10.1029/2009GB003521

Zarco-Tejada, P.J., Miller, J.R., Mohammed, G.H., Noland, T.L., Sampson, P.H., 2002. Vegetation stress detection through chlorophyll $\mathrm{a}+\mathrm{b}$ estimation and fluorescence effects on hyperspectral imagery, in: Journal of Environmental Quality. pp. 1433-1441.

Zhang, Q., Xiao, X., Braswell, B., Linder, E., Baret, F., Moorelll, B., 2005. Estimating light absorption by chlorophyll, leaf and canopy in a deciduous broadleaf forest using MODIS data and a radiative transfer model. Remote Sens. Environ. 99, 357-371. doi:10.1016/j.rse.2005.09.009

Zhao, D., Raja Reddy, K., Kakani, V.G., Read, J.J., Carter, G.A., 2003. Corn (Zea mays L.) growth, leaf pigment concentration, photosynthesis and leaf hyperspectral reflectance properties as affected by nitrogen supply. Plant Soil 257, 205-218. doi:10.1023/A:1026233732507 
Zhao, D., Reddy, K.R., Kakani, V.G., Reddy, V.R., 2005. Nitrogen deficiency effects on plant growth, leaf photosynthesis, and hyperspectral reflectance properties of sorghum. Eur. J. Agron. 22, 391403. doi:10.1016/j.eja.2004.06.005

51119 6

$7^{1121}$

8

91122

10

11

12

13

14

15

16

17

18

19

20

21

22

23

24

25

26

27

28

29

30

31

32

33

34

35

36

37

38

39

40

41

42

43

44

45

46

47

48

49

50

51

52

53

54

55

56

57

58

59

60

61

62

63

64

65 